\title{
Vertebral number is highly evolvable in salamanders and newts (family Salamandridae) and variably associated with climatic parameters
}

\author{
Jan W. Arntzen ${ }^{1,5}$, Wouter Beukema ${ }^{2,3}$, Frietson Galis $^{1}$, Ana Ivanović1, \\ ${ }^{1}$ Naturalis Biodiversity Center, P.O. Box 9517, 2300 RA Leiden, The Netherlands \\ ${ }^{2}$ CIBIO/InBIO, Centro de Investigação em Biodiversidade e Recursos Genéticos da Universidade do Porto. Instituto \\ de Ciências Agrárias de Vairão, Rua Padre Armando Quintas 7, 4485-661 Vairão, Portugal \\ ${ }^{3}$ Departamento de Biologia da Faculdade de Ciências da Universidade do Porto, Porto, Portugal \\ ${ }^{4}$ Faculty of Biology, Institute for Zoology, University of Belgrade, Studentski trg 16, 11000 Belgrade, Serbia \\ ${ }^{5}$ E-mail: pim.arntzen@naturalis.nl
}

Key words: ancestral character states, body shape, climatic niche, comparative method, phylogeny, vertebral column

\begin{abstract}
In vertebrates, the relative proportion of the number of trunk and caudal vertebrae is an important determinant of body shape. While among amphibians frogs and toads show low variation in vertebrae numbers, in salamanders the numbers of trunk and caudal vertebrae vary widely, giving rise to phenotypes in the range from short-bodied and long-tailed to long-bodied and short-tailed. We analysed vertebral numbers in the family Salamandridae in a phylogenetic context and calculated the relationship between vertebral changes and changes in climate and other environmental parameters. A significant association was found between morphological change with precipitation and temperature. However, annual precipitation affected the two main groups of salamandrid salamanders differently, with trunk elongation in the terrestrial 'true salamanders' and tail elongation in the more aquatic 'newts'. A - male biased - sexual dimorphism was only observed in Lissotriton vulgaris vulgaris in the number of trunk vertebrae and in Ommatotriton ophryticus and Lissotriton species for the number of caudal vertebrae. Our data indicated that the number of trunk and caudal vertebrae are highly evolvable traits with frequent evolutionary reversals. In some groups (e.g. Cynops, Lyciasalamandra, Neurergus and the Laotriton-Pachytriton-Paramesotriton clade) the number of trunk vertebrae is stable, while in many groups it is subject to change (e.g. Tylototriton). This latter, species-rich genus appears to be an excellent group to further test effects of the environment on body shape.
\end{abstract}

\section{Contents}

Introduction 85

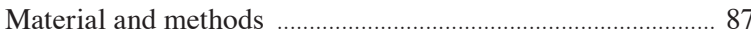

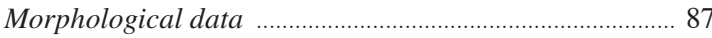

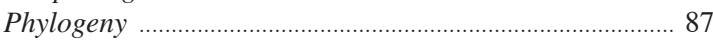

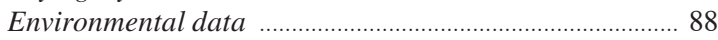

Analyses of character state evolution …………………...... 90

Statistical evaluation .............................................................. 90

Results

Discussion ...
Body shape and climate _...
Evolvability
Conclusions
Acknowledgements
References

\section{Introduction}

A major goal of evolutionary biology is to understand the origin of morphological diversity in the living world. Some morphological features are easily understood in an adaptive context, such as a cryptic versus aposematic colouration and the visibility to potential mates and predators, sturdiness of the skull and fossoriality, or limb length and running speed (e.g. Rettenmeyer, 1970; Gans, 1975; Garland and Janis, 1993; Galis, 1996). However, morphological diversification appears often constrained within lineages. One example concerns the conserved body plans that define the three orders of Amphibia, namely the tailless and compact built frogs and toads (order Anura), the legless, eel-shaped caecilians (order Gymnophiona) and the elongated, legged and tailed salamanders (order Urodela). The short trunk and the absence of a tail in frogs and toads may be an adaptation to digging backwards (Hillenius, 1976) or jumping (Handrigan and Wassersug, 2007). The latter authors further argue that the conservation of the short trunk and the absence of discrete caudal vertebrae in anurans are due to a limited modifiability of the developmental programs involved, which includes activity of the conserved Hox genes. The conservation of the limbless 
caecilian body plan (Nussbaum, 1977; Wake, 1980; Renous and Gasc, 1989) can at least in part be explained by a strong evolutionary constraint on the re-evolution of limbs and digits in amniotes. Mutations for such reevolution are almost invariably accompanied by deleterious pleiotropic effects, which drastically lower fitness (e.g. Lande, 1978; Galis et al., 2010). The body plan of urodeles is also conserved, yet they display considerable variation across families and genera (Litvinchuk and Borkin, 2003; Buckley et al., 2013). In the wellstudied group of Triturus newts, the number of trunk vertebrae appears to be associated with the length of the annual aquatic period (Arntzen, 2003; Ivanović and Arntzen, 2014). The series of five Triturus morphotypes varies from short trunks with 12 vertebrae in species that spend two months in the aquatic environment annually, to elongated trunks with 16 or 17 vertebrae in a species that spends six months in the water annually. This pattern suggests that environmental factors and species-specific ecological preferences may affect the evolutionary changes in the number of trunk vertebrae in salamandrid salamanders. The array of body shapes in salamanders as a function of the number of trunk and caudal vertebrae is illustrated in Fig. 1 for the European and Near-eastern species. The overall pattern of variation, with change along the horizontal axis and along the vertical axis (and not along the diagonal), suggests that the trunk and tail evolve largely independently.

A recent accumulation of morphological data (in particular Lanza et al., 2010), global geo-spatial environmental information and species range maps (Hijmans et al., 2005; IUCN, 2012), and the availability of molecular data for phylogeny building (in particular Babik et al., 2005; Weisrock et al., 2006; Zhang et al., 2008; Wielstra and Arntzen, 2011; Wielstra et al., 2014) forms the basis for the current analysis of body shape variation in the Salamandridae to which more than two-third of European urodele species belong. Our aims are to explore the evolution of body-shape in salamandrid salamanders (family Salamandridae) and to identify potentially important selective environmental

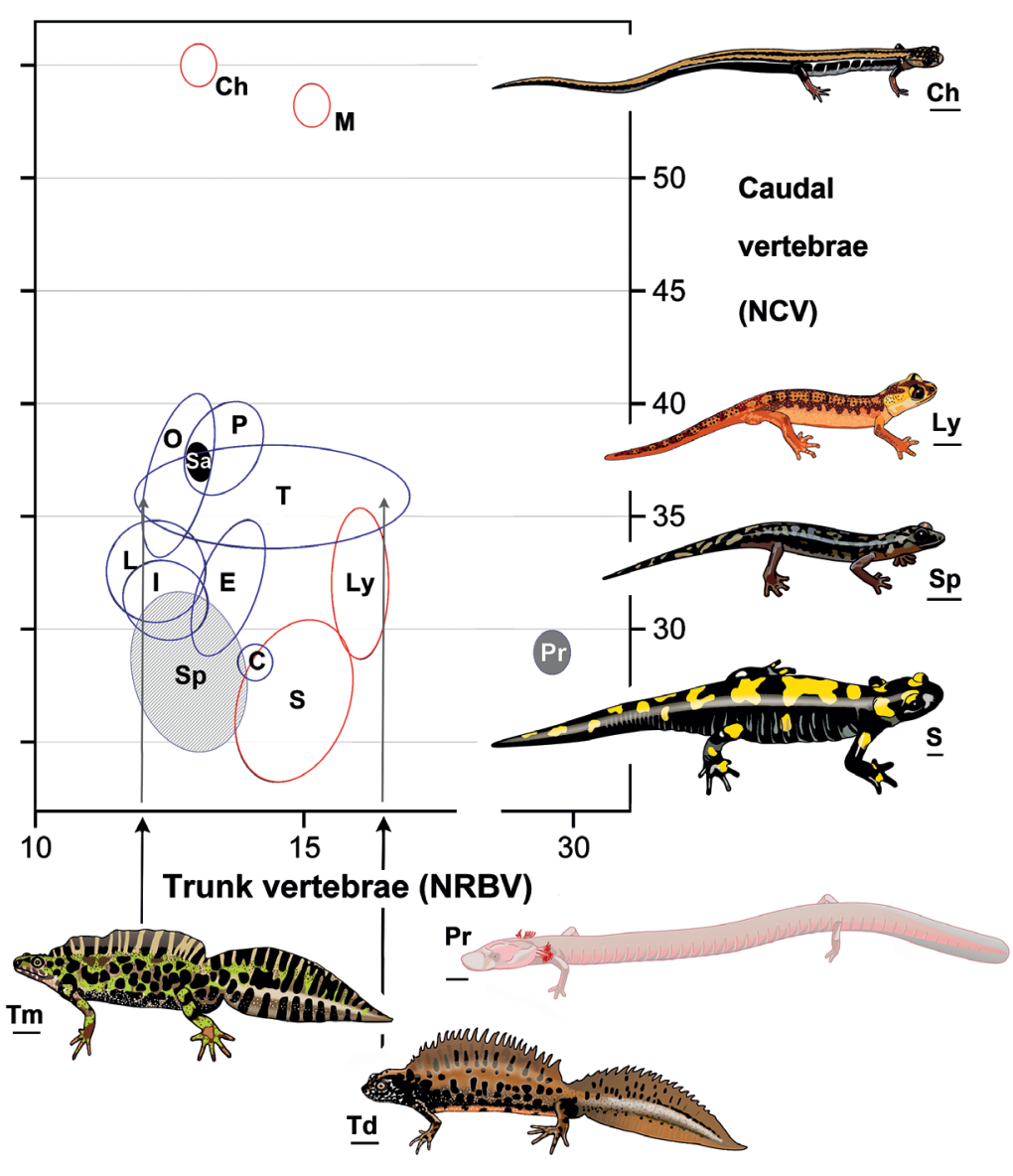

Fig. 1. Schematic representation of the numbers of trunk vertebrae (NRBV, horizontal axis) and caudal vertebrae (NCV, vertical axis) in European representatives of the salamander families Plethodontidae (Sp, light shading), Proteidae (Pr, grey shading) and Salamandridae with the subfamilies Salamandrininae (Sa, in black), Pleurodelinae (or 'newts'- in blue) and Salamandrinae or 'true salamanders' (in red). Data are summarized by ellipses for the genera Calotriton (C), Chioglossa (Ch), Euproctus (E), Ichthyosaura (I), Lissotriton (L), Lyciasalamandra (Ly), Mertensiella (M), Ommatrotriton (O), Pleurodeles (P), Proteus (Pr), Salamandrina (Sa), Salamandra (S), Speleomantes $(\mathrm{Sp})$ and Triturus (T). The extremes are Chioglossa with a short body and a long tail, Speleomantes with a short body and a short tail and Proteus with a long body and short tail, indicating that numbers of trunk and caudal vertebrae may evolve independently. Species highlighted for variation in number of trunk vertebrae, facing left, are Triturus marmoratus (Tm) and T. dobrogicus (Td) representing the Triturus morphoseries. Species highlighted for variation in the number of caudal vertebrae, facing right, are Salamandra infraimmaculata (S), Lyciasalamandra antalaya (Ly) and Chioglossa lusitanica (Ch). Non-salamandrid European urodeles shown for comparisons are Speleomantes flavus $(\mathrm{Sp})$ that lives in and around dry caves and the obligatorily aquatic cave salamander Proteus anguinus (Pr). Drawings are not to scale (size bars underneath species codes indicate $1 \mathrm{~cm}$ ). 
factors by correlating morphological change with climate change in the context of a phylogeny.

\section{Material and methods}

\section{Morphological data}

Data on the number of trunk vertebrae (NRBV) were i) from X-rayed specimens selected from the collection of the Naturalis Biodiversity Center, Leiden. Salamanders were X-rayed on a Faxitron 43855C/D with an exposure of 20-40s at $3 \mathrm{~mA}$ and $70 \mathrm{kV}$; ii) idem, material we borrowed from the Museum of Comparative Zoology, Harvard University, the Museum of Vertebrate Zoology, University of California, Berkeley and the Staatlichen Naturhistorischen Museums, Braunschweig; iii) from cleared and stained specimens from the herpetological collection of the Institute for Biological Research 'Siniša Stanković' (IBISS), Belgrade and iv) data we gathered earlier and were published by Lanza et al. (2010). We scored NRBV in 3439 specimens and the number of caudal vertebrae (NCV) in 1653 specimens. The database was supplemented with records from the literature (Appendix I). For sample sizes per taxon and author names for Salamandridae species see Appendix I.

The NRBV counts excluded the cervical vertebra (atlas) and the sacrum, as in Lanza et al. (2010). In some older publications the counting method could not be ascertained and decisions were made on the basis of consistency of results with other published and our own data. In the case of transitional trunk/sacral vertebra (incomplete homeotic transformation of trunk vertebra into sacral vertebra which produce an asymmetric pelvic articulation), the number of the vertebrae with ribs attached to both sides of the vertebra was counted (e.g. Appendix III H, see also J). The number of specimens with a transitional trunk/sacral homeotic transformation was determined for the samples of X-rayed and cleared and stained specimens. When counting NCV we excluded the sacrum and did not discriminate between caudosacral and caudal vertebrae. When reading from photos, we included all apical elements that were radiographically detectable (see Appendix III and e.g. Fig. 24 in Clergue-Gazeau, 1999 and Fig. 1 in Karakasiliotis et al., 2013).

The intra(sub)specific variation in NRBV is low, with a standard deviation (SD, average weighted for sample size) of 0.53 (data from Lanza et al., 2010). Because SD is markedly lower than unity, NRBV is represented in modal values. In Lissotriton vulgaris vulgaris. Paramesotriton labiatus and Triturus dobrogicus NRBV has two about equally frequent character states; we used the higher values since they appear to represent genuine cases of trunk elongation. Sexual dimorphism (SexDim) was calculated as (value males $_{\text {(val- }}$ $\mathrm{ue}_{\text {males }}+$ value $\left._{\text {females }}\right)$ ). We tested for sexual dimorphism in NRBV with the $G$-test for independence with one degree of freedom for taxa with a sample size $\geq 5$ in both sexes.

The number of caudal vertebrae varied markedly, within and across taxa. Given that the average SD is in excess of unity ( $\mathrm{SD}=2.6$; data from Lanza et al., 2010), $\mathrm{NCV}$ effectively represents a continuum due to which we worked with average group values. Groups considered had a minimum sample size of $n=8$ and included the genera Cynops and Lyciasalamandra and several subspecies of Icthyosaura alpestris and Lissotriton vulgaris. NCV SexDim (as above) was coded as significantly male biased, significantly female biased and the intermediate 'neutral' class as determined with Student's $t$-tests, be it that a female bias did not show in our data.

Trunk elongation by an increase in the number of vertebrae is common in salamanders whereas body elongation through the lengthening of vertebrae without a change in the number, is only known for Pseudoeurycea lineola (Cope, 1865) (Wake, 1991; Parra-Olea and Wake, 2001). Accordingly, vertebral lengthening was not taken into account as a source of variation and, for ease of presentation, we will speak of increase and decrease in the number of trunk and caudal vertebrate as equivalent to the increase / decrease of trunk size and tail size. We ignored the addition of caudal vertebrae and lengthening of the tail throughout life (Noble, 1931; Arntzen, 1994; Babcock and Blais, 2001; Vaglia et al., 2012) because with few exceptions the specimens used in our analyses were adults. We also ignored the possible effects of developmental temperature on meristic characters (Orska and Imiołek, 1962; Jockush, 1997).

\section{Phylogeny}

A phylogeny of most salamandrid species was established from molecular data as detailed in Appendix II. Taxa for which vertebrae counts were absent or insufficient were excluded from the phylogenetic analysis, by a posteriori tree pruning. Accordingly, the number of taxa in the phylogenetic tree was 81 for NRBV and 40 for NCV. The phylogenetic trees are fossil calibrated so that estimates on the timing of character state changes can be made. 


\section{Environmental data}

Mean and standard deviation of 19 'BioClimatic' variables on temperature and precipitation (Bio01 - Bio19) as well as altitude were extracted over the documented range of the (sub)species in ArcGIS 10.0 (ESRI, 2011; data from Hijmans et al., 2005 and IUCN, 2012). From altitude we derived 'slope' using the ArcGIS Spatial Analyst extension. Environmental data for occasional single records (point data representing populations) were extracted over a circular area with $25 \mathrm{~km}$ radius. Missing data points $(<0.4 \%)$ were restricted to Bio03, Bio14 and Biol7 and were filled in by the averages for that variable (Appendix IV). Following the UPGMA clustering of Pearson's correlation coefficient $(r)$, six groups of parameters were recovered at the level of $r<$ 0.5 (Appendix V), from which we selected one variable per group namely Bio01, Bio07, Bio09, Bio12 and
Slope, under the following rationale. 'Annual mean temperature' (Bio01) and 'annual precipitation' (Bio12) represent the most general climate parameters, which are frequently used in amphibian research (Kozak and Wiens, 2012 and references therein). In Triturus newts NRBV appears to be associated with the length of the annual aquatic period (Arntzen, 2003). The climate parameter best expressing desiccation of the ponds that Triturus species use for reproduction is taken to be the 'mean temperature of driest quarter' (Bio09). Alternatively, the length of the aquatic period may be represented by the parameter 'slope' under the rationale that the seasonal presence of large bodies of standing water is more common in flat areas. From the UPGMA clusters not yet represented we included 'precipitation of coldest quarter' (Bio19) and from the remaining cluster we choose the most general parameter, which is 'temperature annual range' (Bio07) (Appen-

Table. 1. Overview on the statistical analyses of morphological evolution in salamandrid salamanders. Abbreviations are: NRBV - number of trunk vertebrae, NCV - number of caudal vertebrae, SexDim - sexual dimorphism and PGLS - phylogenetic generalized least squares.

\begin{tabular}{lllcccc}
\hline Response variable & $\begin{array}{l}\text { Number of taxa in } \\
\text { molecular phylogeny }\end{array}$ & $\begin{array}{l}\text { Method of ancestral } \\
\text { state reconstruction }\end{array}$ & Steps & Gains & Losses & $\begin{array}{l}\text { Testing with stepwise } \\
\text { multiple regression }\end{array}$ \\
\hline NRBV & 81 & parsimony & 29 & 21 & 8 & $\begin{array}{l}\text { logistic } \\
\text { none }\end{array}$ \\
NRBV_SexDim & 81 & parsimony & 1 & 1 & 0 & linear \\
NCV & 40 & PGLS & 136.6 & 57.7 & 78.9 & none \\
NCV_SexDim & 24 & parsimony & 3 & 2 & 1 & \\
\hline
\end{tabular}

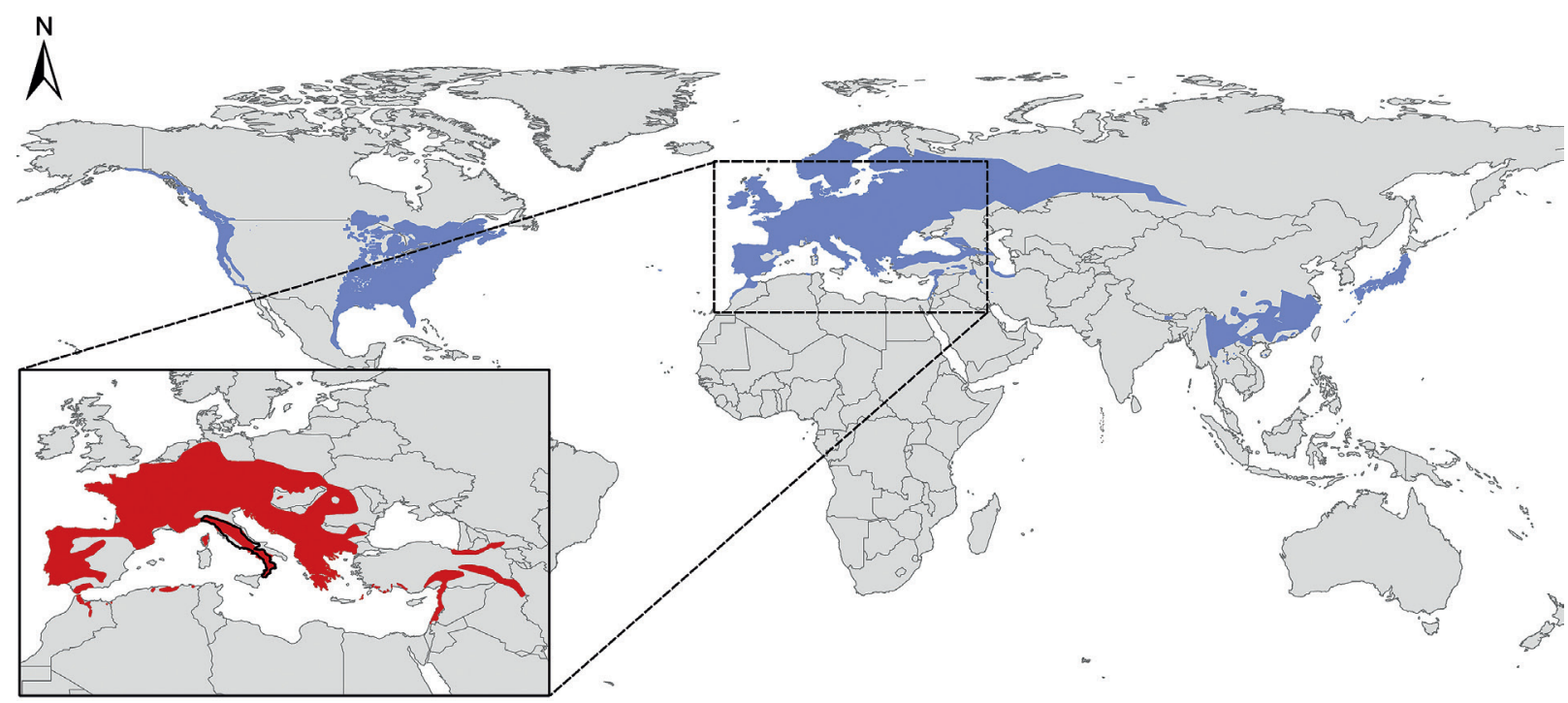

Fig. 2. Global distribution of the family Salamandridae with the 'newts', subfamily Pleurodelinae, in blue, the 'true salamanders' subfamily Salamandrinae in red (inset) and a basal lineage of the subfamily Salamandrininae, genus Salamandrina, in Italy (black outline). 
dix IV). In an additional unguided analysis, we performed principal component analysis based on the correlation matrix (PCA), to reduce the number of explanatory parameters from the 15 not yet considered 'Bio-
Climatic' variables to the number of components with eigenvalues in excess of unity. Selected variables were interpreted in a temporal/phylogenetic framework as described for the continuously distributed morphological variables.

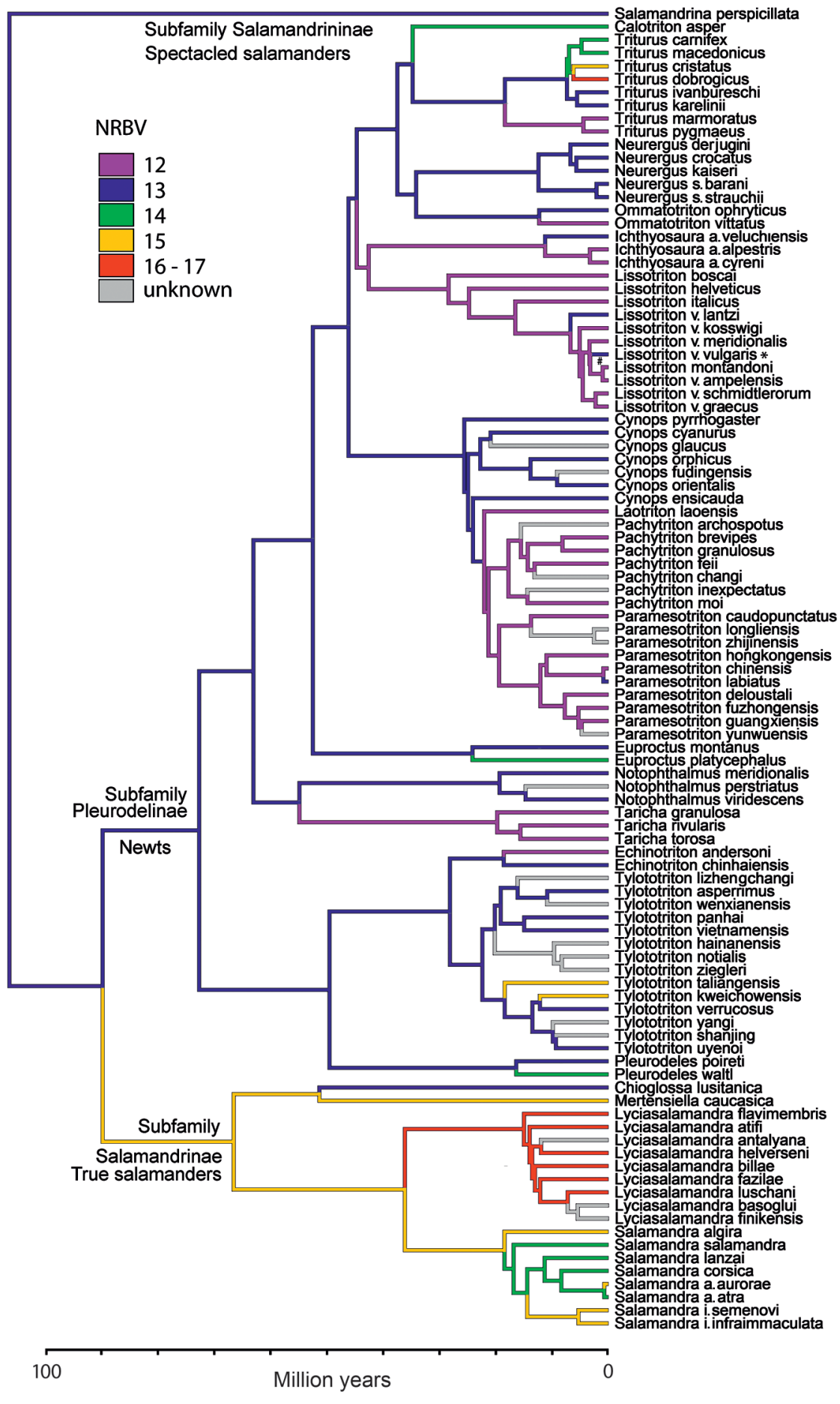

Fig. 3. Calibrated phylogenetic hypothesis for the family Salamandridae constructed from full $\mathrm{mtD}$ NA sequences (43 taxa) and sequences for the ND1 - ND2 mitochondrial genes (58 taxa). NRBV character states are allocated on the basis of 'AccTran' optimization and shown in colour as explained in legend. For details see Appendices I and II. For a representation that emphasizes the direction and possible ambiguity of NRBV character state change see Appendix VII. The taxon marked with an asterisk (*) shows a significant sexually dimorphism and the octothorpe symbol (\#) indicates the branches where change is inferred to have taken place under the parsimony criterion. The phylogenetic position of Lissotriton montandoni is uncertain since this species' original mtDNA has throughout its range been replaced by that of $L$. vulgaris, with which it hybridizes (Babik et al., 2005; Zieliński et al., 2013). 


\section{Analyses of character state evolution}

The number of trunk vertebrae is characterized by a punctuated continuous character state distribution, with modal values for NRBV in the range of 12-17. In the absence of a likelihood-based model to accommodate this transformation series, we applied the parsimony criterion. The program PAUP* (Swofford, 2003) was used to allocate NRBV and SexDim gains and losses over the molecular phylogenetic tree, under 'Acctran' as well as 'Deltran' optimization. Identical results for these methods were interpreted as 'unambiguous' and accordingly the inferred morphological change was linked to a single branch. When the results for both methods were different, this was seen as 'ambiguous' and morphological change was linked to more than one branch (actually, two branches).

For the continuously distributed variables (NCV and the environmental parameters) we explored the data for fit to the Brownian motion (BM) versus OrnsteinUhlenbeck model (OU) of character state change. We compared the ln-likelihood values of the "fitContinuousBM' versus 'fitContinuousOU' model fitting routine of the R (R Core Team, 2012) package Geiger (a program running in R; Harmon et al., 2008). For NCV the Brownian motion model was selected and ancestral character states were estimated with the PGLS (phylogenetic generalized least squares) approach in Compare 4.6b software (http://compare.bio.indiana.edu; see also Martins and Hansen, 1997) in the subroutine 'ancestor reconstruction'. For all environmental parameters OU was the preferred model. The associated constraint alpha was noted for subsequent use in ancestral character state reconstruction. Alpha quantifies the strength of the tendency to move towards the central position of the character state change in the OU model. Alpha values were $<0.1$ in all but three of the analyses. Ancestral character states were estimated with PGLS under the exponential model and alpha values as determined above.

\section{Statistical evaluation}

Statistical analyses were carried out with SPSS 21 (SPSS, 2013). Comparative phylogenetic analyses with NRBV and SexDim gave rise to a binary distribution of inferred gains and inferred losses (i.e., the increase or decrease of vertebrae numbers or sexual dimorphism as seen from the root of the tree). These data were analysed by stepwise logistic regression, in which 'ambiguous' state changes were allocated to all branches where they might have occurred (as in Appendix VII), and then down-weighted as to keep the total number of observations in the analysis unaffected. A second analysis had all branch allocations smaller than unity excluded.

Analysis of NCV yielded the inferred gain versus loss as a continuous variable, alongside with the standard error and associated level of statistical significance. Statistical analyses were performed by means of stepwise multiple regression, for which we considered i) all branches, and ii) all branches on which the morphological change was equal to or in excess of unity.

In stepwise regression analyses, the environmental variables were standardized to an average of zero and standard deviation of unity, to increase the comparability of their effects. Following Garland et al. (1992) all regressions with independent contrasts were forced through the origin. The fit of the descriptive models is expressed by the 'Area Under the Curve in Receiver Operating Characteristic' plots (ROC_AUC, logistic regression) and by Spearman's correlation coefficient $\left(r_{\mathrm{s}}\right.$, linear regression). For a summary of analytical procedures see Table 1 . The groups analysed were the Salamandridae, the 'true salamanders' and the 'newts'; for the global distribution of these groups see Fig. 2.

\section{Results}

The phylogenetic analysis yielded three well-supported major groups (Fig. 3), comprising i) the subfamily Salamandrininae composed of the genus Salamandrina, with an independent history of 106.5 Ma (Million years before present), ii) the subfamily Salamandrinae comprising the 'true salamanders' with a most recent common ancestor (MRCA) at $66.7 \mathrm{Ma}$ and iii) the subfamily Pleurodelinae comprising the 'newts' with a MRCA at 70.5 Ma. The Bayesian posterior probabilities associated with branches in the phylogeny of the Salamandridae are in excess of 0.99 , with few exceptions (see Appendix II). The data on NRBV and NCV across the family Salamandridae are summarized in Appendix I. The frequency of transitional trunk-sacral vertebrae was recorded for 11 newt species and varied between 1\% - 9\% (genus Ichthyosaura 3.0\%, n=93; genus Lissotriton $3.8 \%, \mathrm{n}=277$; genus Triturus $5.1 \%, \mathrm{n}=1261$ ). For the illustration of cleared and stained specimens and X-ray photography see Appendix III. The environmental data extracted from the BioClim data base are presented in Appendix IV.

The character NRBV required 29 steps distributed 


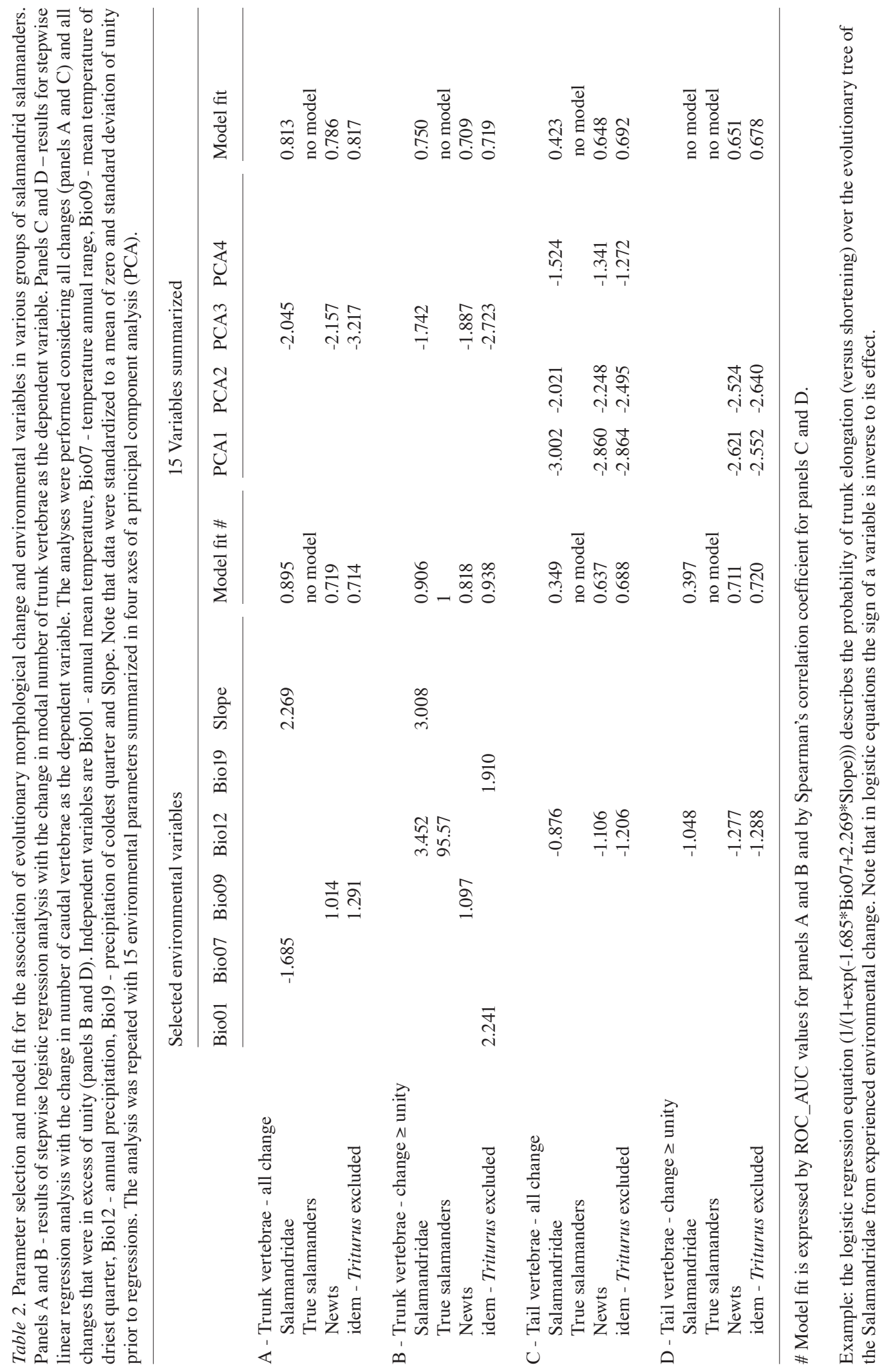




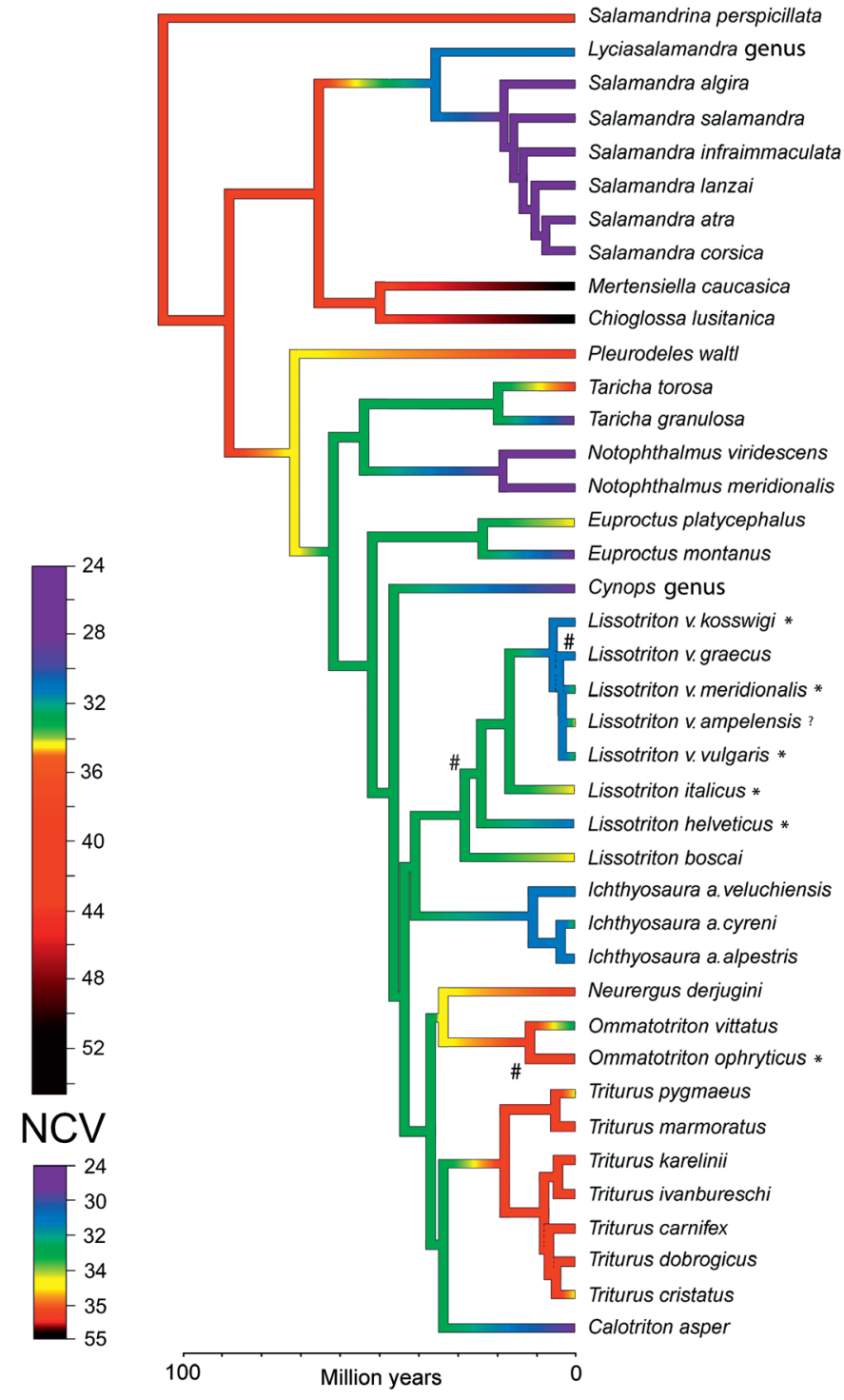

Fig. 4. Calibrated phylogenetic hypothesis for the family Salamandridae with colour coding indicating the average number of caudal vertebrae plotted along the branches (NCV, see text for details). Note that the colour scale is not linear. Taxa marked with an asterisk (*) show significant sexually dimorphism and the octothorpe (\#) indicate the branches where change is inferred to have taken place under the parsimony criterion. over 161 branches of the phylogenetic tree, of which 21 were inferred to be gains and 8 were inferred to be losses (Fig. 3, Appendix VII). This is significantly different from a 50:50 distribution ( $G$-test for goodness of fit, $G=6.04, \mathrm{P}<0.05$ ). The number of ambiguous steps was four in the true salamanders and two in the newts. Under stepwise logistic regression an increase in NRBV was associated with an increase in temperature annual range (Bio07), a decrease in annual precipitation (Bio12) and a decrease in Slope (Table 2AB).

Analysing the true salamanders and the newts separately yielded contrasting results. In the true salamanders we observed a negative relationship with annual precipitation (Bio12, Table 2B). In the newts we observed a negative relationship with the mean temperature of driest quarter (Bio09). The analysis was repeated excluding the genus Triturus, on the rationale that knowledge on this group motivated the parameter selection. This yielded either the same parameter selection (Table 2A) or a different model with Bio01 and Bio19 (Table 2B).

For NCV we observed change over all 79 branches of the phylogenetic tree and 37 changes that were in excess of unity. The total amounts of gains and losses were about the same (Table 1, Fig. 4) and not associated with the distribution of gains versus losses in NRBV 


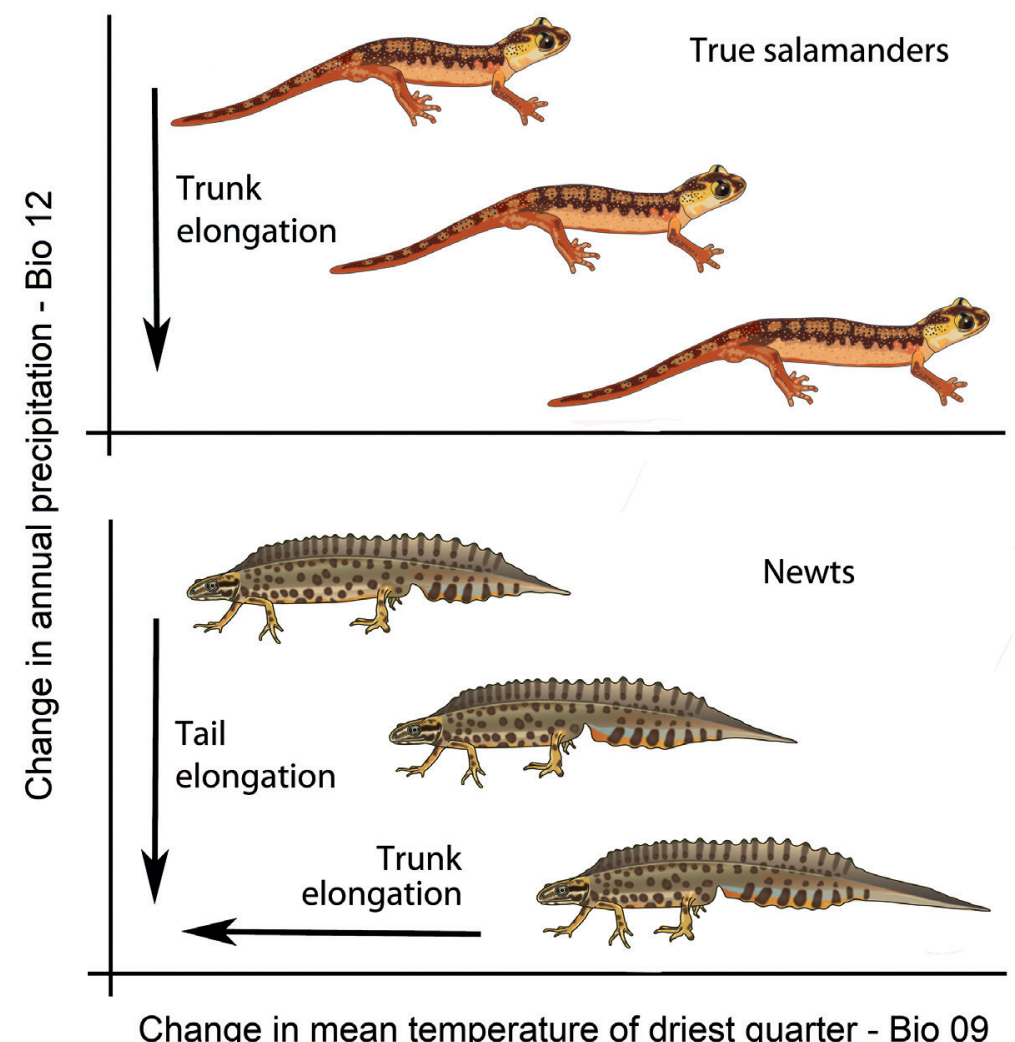

Fig. 5. Schematic representation of the results, in which vertebrae number is interpreted as a size vector. Arrows indicate elongation of the trunk and elongation of the tail as associated with change in the mean temperature of the driest quarter (Bio09, horizontal axis) and with change in annual precipitation (Bio12, vertical axis). Note that the true salamanders (upper panel) and newts (lower panel, Triturus excluded), respond differently to the same climatic parameters. The cartoon images with exaggerated body proportions are drawn after the true salamander Lyciasalamandra antalyana and the newt Lissotriton vulgaris.
( $t$-test, $t=-0.68$, not significant). No models were uncovered with stepwise linear regression for the true salamanders (Table 2CD). When the newts were analysed separately, a negative relationship with the parameter 'annual precipitation' (Bio12) was uncovered, with or without the genus Triturus. The results with analyses on the basis of just those branches carrying morphological change $\geq$ unity were similar. For a pictorial summary of the results see Fig. 5.

We also investigated the 15 non-chosen environmental parameters (Appendix V) as summarized by four PCA axes (Appendix IV C). The first, second, third and fourth axis explain 40.0\%, 27.4\%, 12.1\% and $9.6 \%$ of the total variance, respectively. High loadings $(>0.8)$ on the first axis are by Bio06, Biol1, Biol3 and Biol6 and this axis can be summarized as representing 'cold and wet' environmental conditions. High loadings on the second axis are by $\mathrm{Bio} 02$ and $\mathrm{Biol} 7$ and this axis can perhaps be summarized as 'generally favorable to amphibians' on account of even temperatures (Bio02) and precipitation in periods that it is most needed (Bio17, precipitation of driest quarter). Moderate high loadings $(0.6<$ loading $<0.8)$ on the third axis are by Bio03 and Bio04 and this axis can be summarized as 'temperature fluctuating over the year'. The fourth axis has a moderately high loading of 0.724 by the parameter Altitude. With this approach no models were retrieved for the true salamanders (Table 2). For the newts an increase in NRBV was positively related to PCA3, whereas changes in NCV were positively related to PCA1, PCA2 and sometimes PCA4. However, model fit with 15 variables summarized over four PCA axes was mostly lower than model fit with the pre-selected variables. Moreover, the PCA axes are not straightforward to interpret.

Significant sexual dimorphism in the number of trunk vertebrae was observed only in Lissotriton $v$. vulgaris $(\mathrm{P}<0.0001)$, with a modal score of $\mathrm{NRBV}=13$ in males and $\mathrm{NRBV}=12$ in females, but also we also encountered populations of this subspecies in which sexual dimorphism was absent (results not shown). A significant sexual dimorphism in the number of caudal vertebrae, with males having higher numbers than females, was observed in six groups representing two lineages (the genus Lissotriton, Ommatotriton ophryticus) and involving three evolutionary events (two gains 
and one loss, Fig. 4). Because the number of evolutionary events is low, we refrained from testing for environmental signal possibly underlying the evolution of sexual dimorphism.

\section{Discussion}

\section{Body shape and climate}

Our study shows that climatic factors are significantly associated with numbers of trunk- and caudal vertebrae in the Salamandridae, which is in agreement with the notion that axial pattering in salamanders is to an important extent shaped by the environment (Jockusch, 1997; Blankers et al., 2012). In addition, a significant result in our study is that one environmental parameter (namely the reduction in annual precipitation) affects the two main clades differently, i.e. leading to trunk elongation in the 'true salamanders' and tail elongation in the 'newts' (Fig. 5). Hence, different selection factors, reflecting different climatic niches, appear to be important for the groups of true salamanders and newts. This contrasting response is perhaps not surprising, given that the two groups have long, separate evolutionary histories and differ considerably in development and many life history traits. The most striking difference is the amount of time that they spend in the water or on land, with salamanders being largely terrestrial and newts more aquatic. Additionally, large eggs and embryo- and larval development within oviducts are the rule among the true salamanders, while newts are characterized by small eggs that develop in the surrounding aquatic environment (Thorn, 1969). Prior studies which explored causes underlying axial pattering in salamanders have proposed intrinsic (phylogenetic) as well as extrinsic (environmental) factors to explain the observed variation in body plan (e.g. Wake, 1966; Veith et al., 1992; Jockusch, 1997).

The relationship between trunk and tail length and environmental factors is necessarily complex, since both true salamanders and newts have different ways of locomotion during larval and adult stages and adults have terrestrial and aquatic locomotory modes. Adding to the complexity is the wide array of habitat and climatic variables that are encountered by the species included in our study and more detailed studies are necessary to further interpret our results. Nonetheless, some of the conspicuous differences between true salamanders and newts may give us clues about the differences observed. In true salamanders, trunk elongation may be related to an increased importance of fossoriality in dry circumstances (also proposed for plethodontid salamanders by Jockusch, 1997), as surficial activity strongly depends on precipitation, on which many species of the true salamanders rely for foraging and mating (Duellman and Trueb, 1994). Arguably, when surface activity is restricted due to unsuitable climatic conditions, populations may adopt a more worm-like appearance that facilitates burrowing and the use of small holes and crevices. Indeed, a similar association between fossoriality and axial elongation has been found in lizards (Gans, 1975; Roscito and Rodrigues, 2013). The association between evolution of body form and environmental factors is well known in squamates (Wiens and Sinluff, 2001; Grizante et al., 2012; Roscito and Rodrigues, 2013), which are, among tetrapods, the group with the most variable vertebrae number (Ward and Mehta, 2014). However, for salamanders, a consensus is lacking. An empirical study on a large number of plethodontid salamander species found no clear relationship between body shape and microhabitat use except for a few lineages (Blankers et al., 2012). It seems that the relationship between change in morphology and ecological factors (microhabitat use or climatic parameters) in tailed amphibians is lineagespecific, but further study is necessary to find out to what extent ecological adaptations or lineage-specific constraints are responsible.

In newts, which are dependent on aquatic sites for their reproduction and spend a substantial part of their annual cycle in the water for mating and feeding, a lower mean temperature in the driest quarter (related to the increase in number of trunk vertebrae), and amount of annual precipitation (negatively related to number of caudal vertebrae) may relate to a larger and longer availability of lentic water as a result of low evaporation, which would allow for a longer aquatic phase, with an evolutionary morphological response opposite to that of the true salamanders (Fig. 5).

Locomotor behaviour is among factors that affect morphological evolution and could largely differ among groups and could be phylogenetically constrained (Blomberg et al., 2003). For example, the obligate aquatic urodele Proteus anguinus Laurenti, 1768 - not a salamandrid - has exceptional body proportions with a long trunk and short tail (Fig. 1). This species has an anguilliform swimming mode that is drastically different from the stiff body with movement by tail propulsion in newts such as Triturus spe- 
cies (Gvoždik and Van Damme, 2006). For visual documentation see e.g. http://www.arkive.org/cavesalamander/proteus-anguinus/video-00.html on Proteus anguinus and, at the same address, smooth-newt/ triturus-vulgaris/video-06b.html for Lissotriton vulgaris. To complicate the interpretation further, in species of the semi-aquatic New World brook salamanders of the genus Eurycea the subterranean forms show a shortening of the trunk relative to their surface exploiting counterparts (Bendik et al., 2013).

The relationship between the number of caudal vertebrae and environmental variables is less robust than that found for the number of trunk vertebrae and more study is required to find out which factors affect tail length. It is noteworthy though that the extremely long tails such as found in e.g. Chioglossa lusitanica, a species living in very conditions (Arntzen, 1981, 1994) contrast sharply with the short tails of the Salamandra species, especially those living in arid conditions (Eiselt, 1958) (Fig. 1). At the level of the analyses, we attribute the paucity of significant results to the NRBV changes that could not be linked to a single lineage (four out of eight in the true salamanders versus two out of 21 in the newts, see Appendix VII). Another reason may be the scarcity of data for the number of caudal vertebrae and the limited taxon sampling especially in the true salamanders (see also Ficetola et al., 2013). Indeed, large sample sizes are required to deal with the substantial intraspecific variation in NCV. To circumvent the tedious analyses based upon X-ray imagery, we propose to use tail length relative to snout - vent length as a proxy parameter, provided that centrae-length along the primary body axis is more or less uniform (for extensive data in a variety of urodeles see e.g. Wake, 1966 and Worthington and Wake, 1972). A few X-rays per species would be sufficient to test the assumptions coming with body measurements as proxies to vertebrae counts.

Significant sexual dimorphism in the number of trunk vertebrae was only observed in Lissotriton $v$. vulgaris, but not in all populations, allowing for a study of geographical variation in a search for the underlying causes. Sexual dimorphism in the number of caudal vertebrae was restricted to the two newt genera Lissotriton and Ommatotriton. As it happens these are the groups in which males are larger than females in overall size, suggesting that sexual selection drives the dimorphism (Wiens et al., 2011; Ficetola et al., 2013). For a discussion of sexual dimorphism in the context of Rensch's rule see Colleoni et al. (2014).

\section{Evolvability}

The data here presented indicate a high level of variation in axial pattering in the family Salamandridae, with similar high rates of change over the evolutionary trajectories in true salamanders and in newts. We observed more gains than losses in trunk vertebrae and more or less equal numbers of gains and losses in tail vertebrae. The relatively high frequency of transitional trunk-sacral vertebrae that we observed is in support of the evolvability of the number of trunk vertebrae. It further suggests that evolutionary changes of the trunk count in salamandrid salamanders are due to homeotic changes in the vertebral identity at the trunk-sacral boundary. Transitional vertebrae represent incomplete homeotic transformations (e.g. Varela-Lasheras et al., 2011). Although it is often thought that changes of vertebral count do not necessarily require homeotic transformations and can be solely the result of increases or decreases in the number of vertebrae of a certain region, this is not true, except for vertebrae in the tail region which is the part of the vertebral column formed last. Homeotic transformations are unavoidably involved, because of the sequential head-to-tail generation of the embryonal segments from which the vertebrae develop (somites) and the patterning of these segments under the influence of head-to-tail signaling gradients (for a detailed discussion, see ten Broek et al., 2012). Initial mutations for homeotic transformations usually lead to incomplete transformations. Hence, evolutionary changes of vertebrae counts are only expected if sufficient individuals with transitional vertebrae can survive and reproduce (Galis et al., 2014). The absence of a correlation among changes in number of trunk and caudal vertebrae is not surprising, given that the formation of trunk and caudal vertebrae in vertebrates is decoupled at early development, suggesting that these two parts of the axial skeleton represent independent evolutionary modules and can evolve independently in response to selective pressures (Polly et al., 2001; Ward and Brainerd, 2007; Woltering, 2012).

While the numbers of trunk and caudal vertebrae are variable across urodeles (Jockusch, 1997; Litvinchuk and Borkin, 2003; present study), the number of cervical and sacral vertebrae is highly conserved (one cervical and one sacral vertebra - Duellman and Trueb, 1994). A similar strong constraint has been found for the number of cervical vertebrae in mammals where conservation appears to be explained by the high interactivity of developmental processes at the early developmental stage, during which the number of cervical 
vertebrae is determined, such that a change is invariably associated with other, usually deleterious changes (Galis, 1999; Varela-Lasheras et al., 2011; ten Broek et al., 2012).

The conservation in the number of cervical and sacral vertebra is in strong contrast with the high intraspecific variation in the number of trunk vertebrae in the Salamandridae and in some other urodeles, such as Salamandrella keyserlingii Dybowski, 1870 (Litvinchuk and Borkin, 2003) and the ambystomatid salamanders (Worthington, 1974; Peabody and Brodie, 1975). However, in some lineages such as the genus Bolitiglossa, numerous species have a fixed number of 14 trunk vertebrae, regardless of the length of the trunk (Jockusch, 1997; Parra-Olea and Wake, 2001). 'EcoEvo-Devo' studies are required to find out why the number of trunk vertebrae is conserved in Bolitoglossa and highly evolvable in most other urodele taxa. Our data on a selection of salamanders and newts also indicate that the number of trunk and caudal vertebrae are highly evolvable traits with frequent changes and reversals, affecting both sexes equally. In a few groups however (e.g. Cynops, Lyciasalamandra, Neurergus, and the Laotriton-Pachytriton-Paramesotriton clade) the number of trunk vertebrae is stable, but in most groups it is variable (e.g. Tylototriton). With 18 species (Frost, 2014; Sparreboom, 2014) of which only seven were included in the present study, the latter genus appears an excellent natural group to further investigate effects of the environment on body shape.

\section{Conclusions}

We found significant associations between vertebral column changes and climatic conditions in salamandrid salamanders, with a positive relationship between annual precipitation and axial elongation, manifested through trunk elongation in the terrestrial 'true salamanders' and by tail elongation in the more aquatic 'newts'. Furthermore, we observed a positive relationship between trunk elongation and mean temperature of the driest quarter in 'true salamanders'. Our results support the notion that the selective factors that are important for body shape evolution along environmental gradients differ between the two clades - true salamanders and newts - examined in our study. In addition, we found a high rate of gains and losses of both trunk and caudal vertebrae, indicating significant evolvability of these traits.

\section{Acknowledgements}

We thank John J. Wiens for advice, Dirk van de Marel and Rob Langelaan for X-raying collection material, Esther Dondorp for collection management, Maja Slijepčević for counting vertebrae on cleared and stained specimens from the IBISS collection and Bas Blankevoort for species drawings (copyright Blankevoort (C) Naturalis Biodiversity Center - see also Appendix VI). We thank J. Rosado, J. Hanken and J.B. Losos (Museum of Comparative Zoology, Harvard University), C. Spencer and D.B. Wake (Museum of Vertebrate Zoology, University of California, Berkeley) and U. Joger (Staatlichen Naturhistorischen Museums, Braunschweig) for the loan of specimens under their care. AI acknowledges financial support from the Serbian Ministry of Education and Science (grant no. 173043), grants from SyntheSys (NL-TAF 1245 and 3082) and an NCB Naturalis Temminck fellowship.

\section{References}

Arntzen JW. 1981. Ecological observations on Chioglossa lusitanica (Caudata, Salamandridae). Amphibia-Reptilia 1: 187203.

Arntzen JW. 1994. Allometry and autotomy of the tail in the Golden-striped salamander, Chioglossa lusitanica. Amphibia-Reptilia 15: 267-274.

Arntzen JW. 2003. Triturus cristatus Superspecies - KammolchArtenkreis, Triturus cristatus (Laurenti, 1768) - Nördlicher Kammolch, Triturus carnifex (Laurenti, 1768) - Italienischer Kammolch, Triturus dobrogicus (Kiritzescu, 1903) - DonauKammolch, Triturus karelinii (Strauch, 1870) - Südlicher Kammolch). Pp. 421-514 in: Grossenbacher K, Thiesmeier B, ed., Handbuch der Reptilien und Amphibien Europas Schwanzlurche IIA. Aula-Verlag, Wiebelsheim, Germany.

Babcock SK, Blais JL. 2001. Caudal vertebral development and morphology in three salamanders with complex life cycles (Ambystoma jeffersonianum, Hemidactylium scutatum, and Desmognathus ocoee). Journal of Morphology 247: 142-159.

Babik W, Branicki W, Crnobrnja-Isailović J, Cogalniceanu D, Sas I, Olgun K, Poyarkov NA, García-París M, Arntzen JW. 2005. Phylogeography of two European newt species - discordance between mtDNA and morphology. Molecular Ecology 14: 2475-2491.

Bendik NF, Meik JM, Gluesenkamp AG, Roelke CE, Chippindale PT. 2013. Biogeography, phylogeny, and morphological evolution of central Texas cave and spring salamanders. BMC Evolutionary Biology 13: 201. doi: 10.1186/1471-2148-13-201

Blankers T, Adams DC, Wiens JJ. 2012. Ecological radiation with limited morphological diversification in salamanders. Journal of Evolutionary Biology 25: 634-646.

Blomberg SP, Garland T, Ives AR, 2003. Testing for phylogenetic signal in comparative data: behavioural traits are more labile. Evolution 57: 717-745

Böhme M. 2003. The Miocene climatic optimum: evidence from ectothermic vertebrates of Central Europe. Palaeogeography, Palaeoclimatology, Palaeoecology 195: 389-401.

Böhme W, Schöttler T, Nguyen QT, Köhler J. 2005. A new species of salamander, genus Tylototriton (Urodela: Salamandridae), from northern Vietnam. Salamandra 41: 215-220. 
Broek CMA ten, Bakker AJ, Varela-Lasheras I, Bugiani M, Dongen S van, Galis F. 2012. Evo-devo of the human vertebral column: on homeotic transformations, pathologies and prenatal selection. Evolutionary Biology 39: 456-471.

Buckley D, Molnár V, Németh G, Petneházy Ö, Vörös J. 2013. Monster... -omics': on segmentation, re-segmentation, and vertebrae formation in amphibians and other vertebrates. Frontiers in Zoology 10: 17. doi: 10.1186/1742-9994-10-17

Carranza S, Wade E. 2004. Taxonomic revision of Algero-Tunisian Pleurodeles (Caudata: Salamandridae) using molecular and morphological data. Revalidation of the taxon Pleurodeles nebulosus (Guichenot, 1850). Zootaxa 488: 1-24.

Carranza S, Amat F. 2005. Taxonomy, biogeography and evolution of Euproctus (Amphibia: Salamandridae), with the resurrection of the genus Calotriton and the description of a new endemic species from the Iberian peninsula. Zoological Journal of the Linnean Society 145: 555-582.

Chan LM, Zamudio KR, Wake DB. 2001. Relationships of the salamandrid genera Paramesotriton, Pachytriton, and $C y$ nops based on mitochondrial DNA sequences. Copeia 2001: 997-1009.

Chang MLY. 1932. Notes on two salamanders from Chekiang. Contributions from the Biological Laboratory of the Science Society of China. Zoological Series 8: 201-212.

Clergue-Gazeau M. 1999. Euproctus asper (Dugès, 1852) - Pyrenäen-Gebirgsmolch. Pp. 251-269 in: Grossenbacher K, Thiesmeier B, ed., Handbuch der Reptilien und Amphibien Europas Schwanzlurche I. Aula-Verlag, Wiebelsheim, Germany.

Colleoni E, Denoel M, Padoa-Schioppa E, Scali S, Ficetola GF. 2014. Rensch's rule and sexual dimorphism in salamanders: patterns and potential processes. Journal of Zoology 293: 143-151.

Darriba D, Taboada GL, Doallo R, Posada D. 2012. jModelTest 2: more models, new heuristics and parallel computing. $\mathrm{Na}$ ture Methods 9: 772.

Drummond AJ, Ho SYW, Phillips MJ, Rambaut A. 2006. Relaxed phylogenetics and dating with confidence. PLoS Biology 4: 699-710.

Drummond AJ, Rambaut A. 2007. BEAST: Bayesian evolutionary analysis by sampling trees. BMC Evolutionary Biology 7: 214. doi: 10.1186/1471-2148-7-214

Duellman WE, Trueb L. 1994. Biology of Amphibians. Johns Hopkins University Press. Baltimore, Maryland, USA.

Eiselt J. 1958. Der Feuersalamander Salamandra salamandra (L.). Beiträge zu einer taxonomischen Synthese. Abhandlungen und Berichte für Naturkunde und Vorgeschichte Magdeburg 10: 77-154.

ESRI. 2011. ArcGIS Desktop: Release 10. Redlands, CA: Environmental Systems Research Institute.

Estes R. 1981. Gymnophiona, Caudata. Pp. 1-15 in: Wellnhofer P, ed., Handbuch der Palaeoherpetologie, Part 2. Gustav Fischer, Stuttgart, Germany.

Ficetola GF, Bonardi A, Colleoni E, Padoa-Schioppa E, Scali S. 2013. Evolution of sexual dimorphism in the number of tail vertebrae in salamanders: comparing multiple hypotheses. Evolutionary Biology 40: 220-227.

Frost DR. 2014. Amphibian species of the world: an online reference. Version 6.0 (date of access April 7, 2014). Electronic database accessible at http://research.amnh.org/herpetology/ amphibia/index. html. American Museum of Natural History, New York, USA.
Galis F. 1996. The application of functional morphology to evolutionary studies. Trends in Ecology and Evolution 11: 124-129.

Galis F. 1999. Why do almost all mammals have seven cervical vertebrae? Developmental constraints, Hox genes and cancer. Journal of Experimental Zoology. Molecular and Developmental Evolution 285B: 19-26.

Galis F, Arntzen JW, Lande R. 2010. Dollo's law and the irreversibility of digit loss in Bachia. Evolution 64: 24662476.

Galis F, Carrier DR, Alphen J van, Mije S van der, Dooren T van, Metz JAJ, ten Broek CMA. 2014. Fast running restricts evolutionary change of the vertebral column in mammals. Proceedings of the National Academy of Sciences 111: 11401-11406.

Gans C. 1975. Tetrapod limbless: the evolution of functional correlates. American Zoologist 15: 445-467.

Garland T, Janis CM. 1993. Does metatarsal/femur ratio predict maximal running speed in cursorial mammals? Journal of Zoology 229: 133-151.

Garland T, Harvey PH, Ives AR. 1992. Procedures for the analysis of comparative data using phylogenetically independent contrasts. Systematic Biology 41: 18-32.

Grizante MB, Brandt R, Kohlsdorf T. 2012. Evolution of body elongation in Gymnophthalmid lizards: relationships with climate. PLoS ONE 7. doi: 10.1371/journal.pone.0049772

Gvoždik L, Damme R van. 2006. Triturus newts defy the running-swimming dilemma. Evolution 60: 2110-2121.

Handrigan GR, Wassersug RJ. 2007. The anuran Bauplan: a review of the adaptive, developmental, and genetic underpinnings of frog and tadpole morphology. Biological Reviews 82: $1-25$.

Harmon LJ, Weir J, Brock C, Glor RE, Challenger W. 2008. GEIGER: Investigating evolutionary radiations. Bioinformatics 24: 129-131.

Haubold H, Thomae M. 1990. Stratigraphische Revision der Wirbeltierfundstellen des Geiseltaleozaens. Hallesches Jahrbuch für Geowissenschaften 15: 3-20.

Hijmans RJ, Cameron SE, Parra JL, Jones PG, Jarvis A. 2005. Very high resolution interpolated climate surfaces for global land areas. International Journal of Climatology 25: 19651978.

Hillenius D. 1976. On the origin of the anuran body form (Amphibia: Anura). Beaufortia 25: 63-77.

IUCN. 2012. The IUCN Red List of Threatened Species. Version 2012.2. Data accessible at http://www.iucnredlist.org.

Ivanov M. 2008. Early Miocene amphibians (Caudata, Salientia) from the Mokra-Western Quarry (Czech Republic) with comments on the evolution of Early Miocene amphibian assemblages in Central Europe. Geobios 41: 465-492.

Ivanović A, Arntzen JW. 2014. Evolution of skull and body shape in Triturus newts reconstructed from three-dimensional morphometric data and phylogeny. Biological Journal of the Linnean Society 113: 243-255.

Jockusch EL. 1997. Geographic variation and phenotypic plasticity of number of trunk vertebrae in slender salamanders, Batrachoseps (Caudata: Plethodontidae). Evolution 51: 19661982.

Karakasiliotis K, Schilling N, Cabelguen J-M, Ijspeert AJ. 2013. Where are we in understanding salamander locomotion: biological and robotic perspectives on kinematics. Biological Cybernetics 107: 529-544. 
Kozak KH, Wiens JJ. 2012. Phylogeny, ecology, and the origins of climate-richness relationships. Ecology 93: 167-181.

Lande R. 1978. Evolutionary mechanisms of limb loss in tetrapods. Evolution 32: 73-92.

Lanza B, Arntzen JW, Gentile E. 2010. Vertebral numbers in the Caudata of the Western Palaeartic (Amphibia). Atti del Museo Civico di Storia Naturale di Trieste 54: 3-114.

Litvinchuk SN, Borkin LJ. 2003. Variation in number of trunk vertebrae and in count of costal grooves in salamanders of the family Hynobiidae. Contributions to Zoology 72: 195209.

Litvinchuk SN, Zuiderwijk A, Borkin LJ, Rosanov M. 2005. Taxonomic status of Triturus vittatus (Amphibia: Salamandridae. in western Turkey: trunk count, genome size and allozyme data. Amphibia-Reptilia 26: 305-323.

Liu C-C. 1950. Amphibians of western China. Fieldiana Zoology Memoirs, Volume 2. Chicago Natural History Museum, Chicago, USA.

Maddison DR, Maddison WP. 2000. MacClade 4. Sinauer Associates, Inc., Sunderland, Massachusetts, USA.

Martins EP, Hansen TF. 1997. Phylogenies and the comparative method: A general approach to incorporating phylogenetic information into the analysis of interspecific data. American Naturalist 149: 646-667.

Mertz DF, Swisher CC, Franzen JL, Neuffer FO, Lutz H. 2000. Numerical dating of the Eckfeld maar fossil site, Eifel, Germany: a calibration mark for the Eocene time scale. Naturwissenschaften 87: 270-274.

Milner AR. 2000. Mesozoic and Tertiary Caudata and Albanerpetontidae. Pp. 31-108 in: Heatwole H, Carroll RJ, editors. Amphibian Biology. Vol. 4. Surrey Beatty, Chipping Norton, Australia.

Nadachowska K, Babik W. 2009. Divergence in the face of gene flow: the case of two newts (Amphibia: Salamandridae). Molecular Biology and Evolution 26: 829-841.

Nishikawa K, Jiang J-P, Matsui M. 2011a. Two new species of Pachytriton from Anhui and Guangxi, China (Amphibia: Urodela: Salamandridae). Current Herpetology 30: 15-30.

Nishikawa K, Jiang J-P, Matsui M, Mo Y-M. 2011b. Unmasking Pachytriton labiatus (Amphibia: Urodela: Salamandridae), with description of a new species of Pachytriton from Guangzi, China. Zoological Science 28: 453-461.

Nishikawa K, Matsui M, Nguyen TT. 2013a. A new species of Tylototriton from Northern Vietnam (Amphibia: Urodela: Salamandridae). Current Herpetology 32: 34-49.

Nishikawa K, Khonsue W, Pomchote P, Matsui M. 2013b. Two new species of Tylototriton from Thailand (Amphibia: Urodela: Salamandridae). Zootaxa 3737: 261-279.

Noble GK. 1931. The Biology of the Amphibians. First edition. McGraw Hill, New York, USA.

Nussbaum RA. 1977. Rhinatrematidae: a new family of caecilians (Amphibia: Gymnophiona). Occasional Papers Museum of Zoology, University of Michigan 682: 1-30.

Nussbaum RA, Brodie ED. 1982. Partitioning of the salamandrid genus Tylototriton Anderson (Amphibia: Caudata) with a description of a new genus. Herpetologica 38: 320-332.

Nylander JAA. 2004. MrModeltest v2. Program distributed by the author. Evolutionary Biology Centre, Uppsala University, Uppsdala, Sweden.

Orska J, Imiołek Z. 1962. Preliminary studies on the effect of temperature on the development of meristic characters in the
Urodela. (in Polish with English summary). Acta Universitatis Wratislaviensis. Prace zoologiczne 1: 135-155.

Page RDM. 1996. TreeView: An application to display phylogenetic trees on personal computers. Computer Applications in the Biosciences 12: 357-358.

Parra-Olea G, Wake DB. 2001. Extreme morphological and ecological homoplasy in tropical salamanders. Proceedings of the National Academy of Sciences USA 98: 7888-7891.

Peabody RB, Brodie ED. 1975. Effect of temperature, salinity and photoperiod on the number of trunk vertebrae in Ambystoma maculatum. Copeia 1975: 741-746.

Polly PD, Head JJ, Cohn MJ. 2001. Testing modularity and dissociation: the evolution of regional proportions in snakes (Serpentes, Vertebrata). Pp. 305-335 in: Zelditch M, editor. Beyond Heterochrony: The Evolution of Development. John Wiley Sons, New York, USA.

Qiu ZX, Qiu ZD. 1995. Chronological sequence and subdivision of Chinese Neogene mammalian faunas. Palaeogeography, Palaeoclimatology, Palaeoecology 116: 41-70.

R Development Core Team. 2012. R: A language and environment for statistical computing. R Foundation for Statistical Computing, Vienna, Austria. URL http://www.R-project.org.

Renous S, Gasc JP. 1989. Body and vertebral proportions in Gymnophiona (Amphibia): diversity of morphological types. Copeia 1989: 837-847.

Rettenmeyer CW. 1970. Insect mimicry. Annual Review of Entomology 15: 43-74.

Roscito JG, Rodrigues MT. 2013. A comparative analysis of the post-cranial skeleton of fossorial and non-fossorial gymnophthalmid lizards. Journal of Morphology 274: 845-858.

Rubinoff D, Holland BS. 2005. Between two extremes: mitochondrial DNA is neither the Panacea nor the Nemesis of phylogenetic and taxonomic inference. Systematic Biology 54: 952-961.

Skorinov DB, Litvinchuk SN. 2012. Axial skeleton variation in newts of the genus Lissotriton: Comparative-evolutionary study. Pp. 285-288 in: The Problems of Herpetology. Proceedings of the 5th Congress of the Alexander M. Nikolsky Herpetological Society. Russian Academy of Sciences. Minsk, Russia.

Smith SA, Dunn CW. 2008. PhyUtility: a phyloinformatics tool for trees, alignments, and molecular data. Bioinformatics 24 : 715-716.

Sparreboom M. 2014. Salamanders of the Old World. KNNV, Zeist, The Netherlands.

SPSS. 2013. SPSS 21. Statistical Package for the Social Sciences. SPSS Inc, Chicago, USA.

Steinfartz S, Vicario S, Arntzen JW, Caccone A. 2007. A Bayesian approach on molecules and behavior: reconsidering phylogenetic and evolutionary patterns of the Salamandridae with emphasis on Triturus newts. Journal of Experimental Zoology, Molecular and Developmental Evolution 308B: 139-162.

Stuart BL, Papenfuss TJ. 2002. A new salamander of the Genus Paramesotriton (Caudata: Salamandridae) from Laos. Journal of Herpetology 36: 145-148.

Stuart BL, Phimmachak S, Sivongxay N, Robichaud WG. 2010. A new species in the Tylototriton asperrimus group (Caudata: Salamandridae) from central Laos. Zootaxa 2650: 19-32.

Swofford DL. 2003. PAUP*. Phylogenetic Analysis Using Parsimony (*and Other Methods). Version 4. Sinauer Associates, Sunderland, Massachusetts, USA. 
Thorn R. 1969. Les Salamandres d'Europe, d'Asie et d'Afrique $d u$ Nord. Editions Paul Lechevalier, Paris, France.

Vaglia JL, White K, Case A. 2012. Evolving possibilities: postembryonic axial elongation in salamanders with biphasic (Eurcyea cirrigera, Eurycea longicauda, Eurycea quadridigitata) and paedomorphic life cycles (Eurycea nana and Ambystoma mexicanum). Acta Zoologica, Stockholm 93: 2-13.

Varela-Lasheras I, Bakker AJ, Mije S van der, Alphen J van, Galis F. 2011. Breaking evolutionary and pleiotropic constraints in mammals: on sloths, manatees and homeotic mutations. EvoDevo 2: 11. doi: 10.1186/2041-9139-2-11

Veith M, Degani G, Seitz A. 1992. Discordance of genetical and morphological variation of Salamandra salamandra (L.) in Israel. Zoologischer Anzeiger 229: 63-72.

Vukov TD, Sotiropoulos K, Kalezić M, Džukić G. 2011. Morphing of the phylogeographic lineages of the Balkan alpine newts (Ichthyosaura alpestris, Caudata, Salamandridae): In situ morphological diversification. Comptes Rendus Biologies 334: 896-905.

Wake DB. 1966. Comparative osteology and evolution of the lungless salamanders, family Plethodontidae. Memoirs of the Southern California Academy of Sciences 4: 1-111.

Wake DB. 1991. Homoplasy: the result of natural selection or evidence of design limitations. American Naturalist 138: 543-567.

Wake MH. 1980. Morphometrics of the skeleton of Dermophis mexicanus (Amphibia: Gymnophiona). Part I. The vertebrae, with comparisons to other species. Journal of Morphology 165: 117-130.

Ward AB, Brainerd EL. 2007. Evolution of axial patterning in elongate fishes. Biological Journal of the Linnean Society 90: 97-116.

Ward AB, Mehta RS. 2014. Differential occupation of axial morphospace. Zoology 117: 70-76.

Weisrock DW, Papenfuss TJ, Macey JR, Litvinchuk SN, Polymeni R, Ugurtas IH, Zhao E, Jowkar H, Larson A. 2006. A molecular assessment of phylogenetic relationships and lineage accumulation rates within the family Salamandridae (Amphibia, Caudata). Molecular Phylogenetics and Evolution 41: 368-383.

Wen Y. 1989. A new species of the genus Paramesotriton (Amphibia: Caudata. from Guangxi and a comparison with $P$. guangxiensis. Chinese Herpetological Research 2: 15-20.

Wielstra B, Arntzen JW. 2011. Unraveling the rapid radiation of crested newts (Triturus cristatus superspecies. using complete mitogenomic sequences. BMC Evolutionary Biology 11: 162. doi: 10.1186/1471-2148-11-162

Wielstra B, Arntzen JW, Gaag K van der, Pabijan M, Babik W. 2014. Data concatenation, Bayesian concordance and coalescent-based analyses of the species tree for the rapid radiation of Triturus newts. Plos ONE 9: e111011. doi: 10.1371/journal. pone. 0111011

Wiens JJ. 2007. Global patterns of species richness and diversification in amphibians. American Naturalist 170: S86-S106.

Wiens JJ, Slingluff JL. 2001. How lizards turn into snakes: a phylogenetic analysis of body-form evolution in anguid lizards. Evolution 55: 2303-2318.

Wiens JJ, Sparreboom M, Arntzen JW. 2011. Crest evolution in newts: implications for reconstruction methods, sexual selection, phenotypic plasticity and the origin of novelties. Journal of Evolutionary Biology 24: 2073-2086.
Woltering JM. 2012. From lizard to snake. Behind the evolution of an extreme body plan. Current Genomics 13: 289-299.

Worthington RD. 1974. High incidence of anomalies in a natural population of spotted salamander, Ambystoma maculatum. Herpetologia 30: 216-220.

Worthington RD, Wake DB. 1972. Patterns of regional variation in the vertebral column of terrestrial salamanders. Journal of Morphology 137: 257-277.

Wu Y, Rovito SM, Papenfuss TJ, Hanken J. 2009. A new species of the genus Pachytriton (Caudata: Salamandridae) from Guangxi Zhuang autonomous region, southern China. Zootaxa 2060: 59-68.

Wu Y, Wang Y, Jiang K, Hanken J. 2010a. A new newt of the genus Cynops (Caudata: Salamandridae) from Fujian Province, southeastern China. Zootaxa 2346: 42-52.

Wu Y, Wang Y, Jiang K, Chen X, Hanken J. 2010b. Homoplastic evolution of external coloration in Asian stout newts (Pachytriton) inferred from molecular phylogeny. Zoologica Scripta 39: 9-22.

Wu Y, Jiang K, Hanken J. 2010c. A new species of newt of the genus Paramesotriton (Salamandridae) from southwestern Guangdong, China, with a new northern record of $P$. longliensis from western Hubei. Zootaxa 2494: 45-58.

Wu Y, Wang Y, Hanken J. 2012a. New species of Pachytriton (Caudata: Salamandridae) from the Nanling mountain range, southeastern China. Zootaxa 3388: 1-16.

Wu Y, Wang Y, Hanken J. 2012b. Comparative osteology of the genus Pachytriton (Caudata: Salamandridae) from southeastern China. Asian Herpetological Reseach 3: 83-102.

Wu Y, Wang Y, Jiang K, Hanken J. 2013. Significance of preQuaternary climate change for montane species diversity: Insights from Asian salamanders (Salamandridae: Pachytriton). Molecular Phylogenetics and Evolution 66: 380390.

Yu P, Zhao E. 2007. Research of the skeleton system of Tylototriton kweichowensis. (In Chinese with English summary). Sichuan Journal of Zoology 26: 133-137 [140].

Yuan Z, Jiang K, Ding L, Zhang L, Che J. 2013. A new newt of the genus Cynops (Caudata: Salamandridae) from Guangdong, China. Asian Herpetological Research 4: 116-123.

Zajc I, Arntzen JW. 1999. Pylogenetic relationships of the European newts (genus Triturus) tested with mitochondrial DNA sequence data. Contributions to Zoology 68: 73-81.

Zhang P, Papenfuss TJ, Wake MH, Qu L, Wake DB. 2008. Phylogeny and biogeography of the family Salamandridae (Amphibia: Caudata) inferred from complete mitochondrial genomes. Molecular Phylogenetics and Evolution 49: 586-597.

Zhao E, Hu Q, Jiang Y, Yang Y. 1988. Studies on Chinese salamanders. Society for the Study of Amphibians and Reptiles in cooperation with the Herpetological Society of Japan and Japan Wildlife Research Center, Oxford, Ohio, USA.

Zieliński P, Nadachowska-Brzyska K, Wielstra B, Szkotak R, Covaciu-Marcov SD, Cogălniceanu D, Babik W. 2013. No evidence for nuclear introgression despite complete mtDNA replacement in the Carpathian newt (Lissotriton montandoni). Molecular Ecology 22: 1884-1903.

Received: 31 Januari 2014

Revised and accepted: 19 November 2014

Published online: 29 April 2015

Editor: M. Brazeau 


\section{Online Supplementary Information}

S1. ND1 and ND2 sequence data underlying thev phylogeny of the Salamandridae (Fig. 3, Appendix I) in NEXUS format. The full mitogenomic data can be found at the TreeBase repository under the numbers S9945 and S11081. 


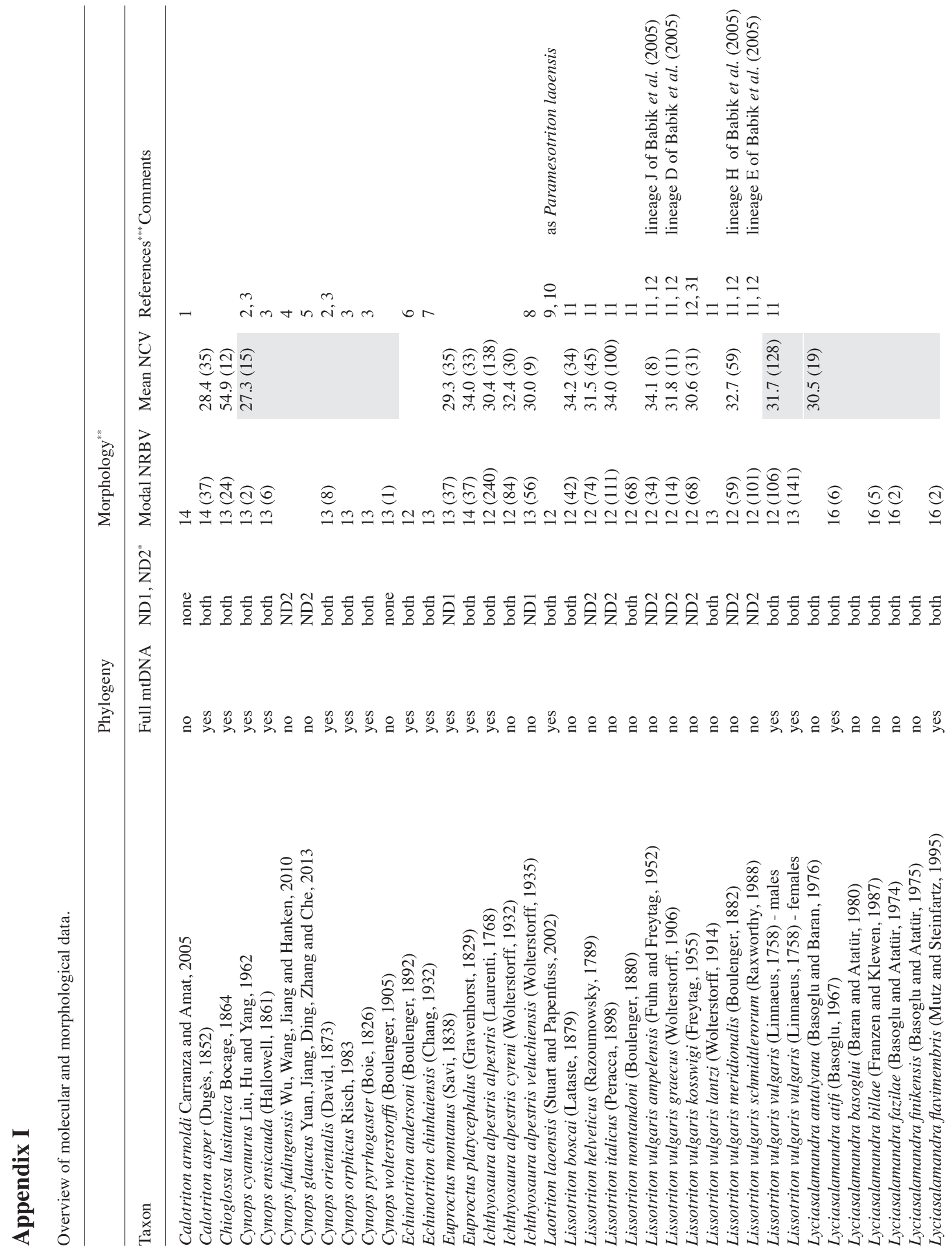




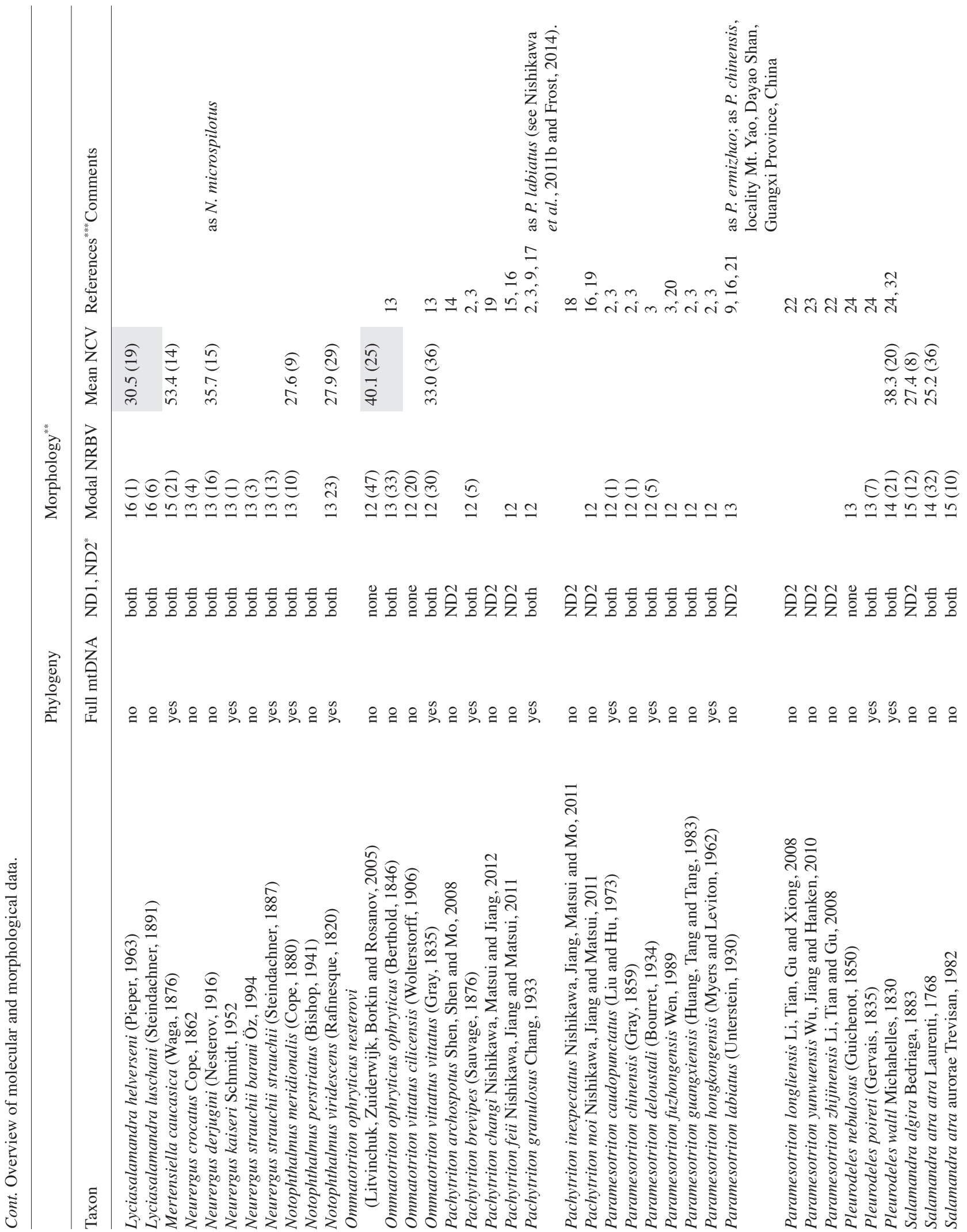




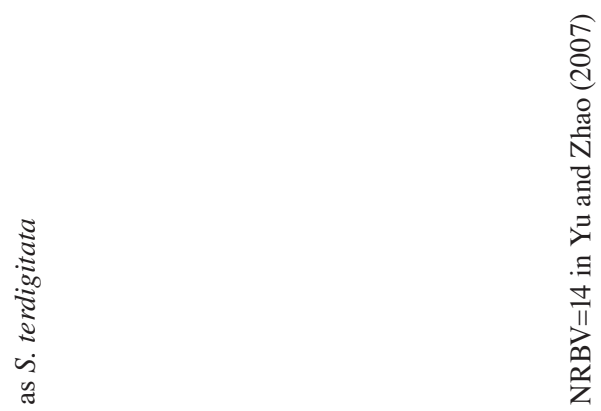

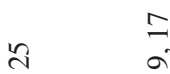

@

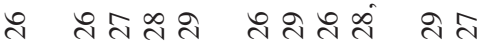

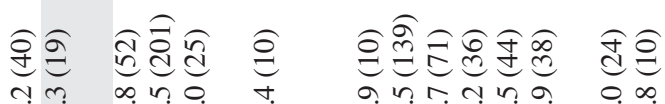

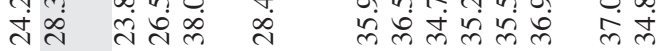

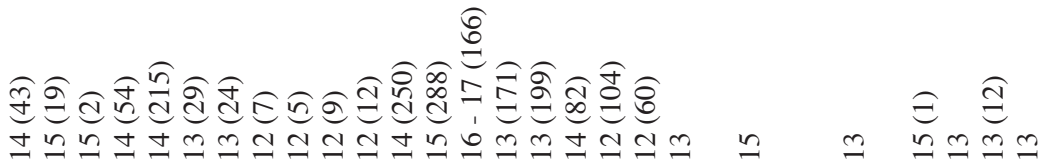

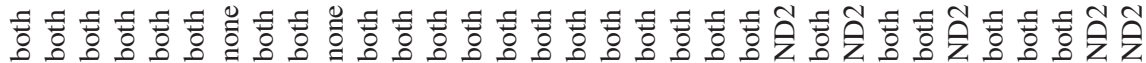

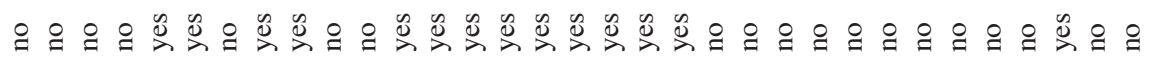

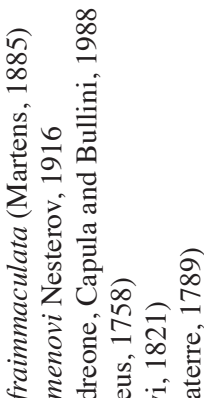

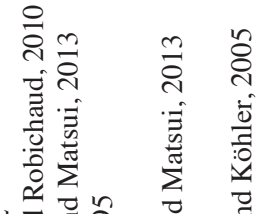

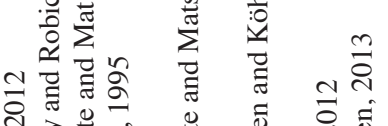

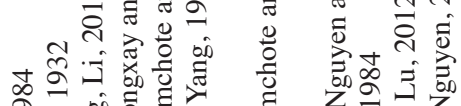

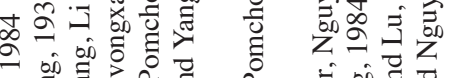

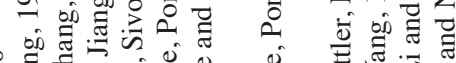

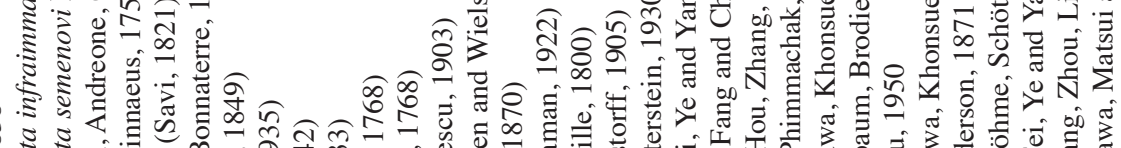

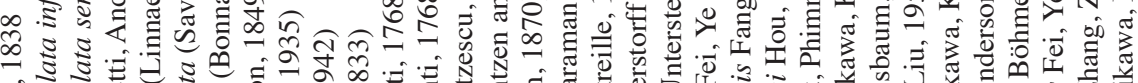

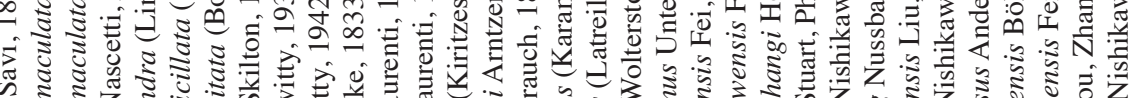

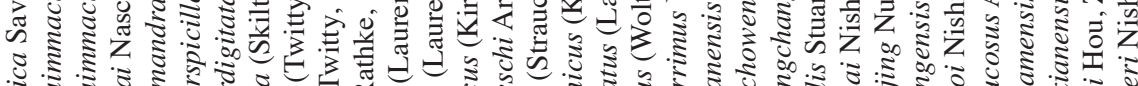

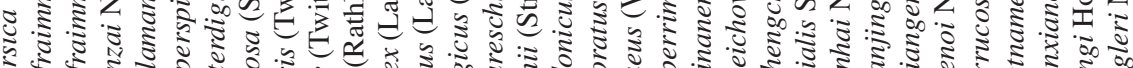

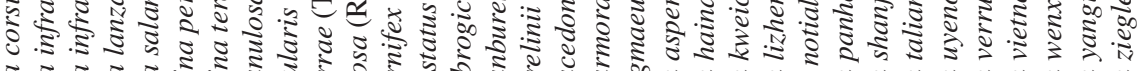
M

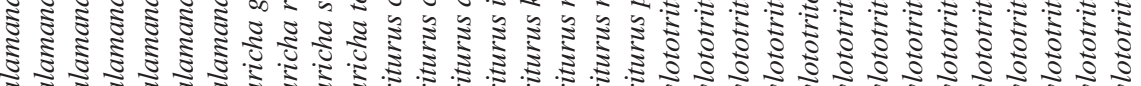

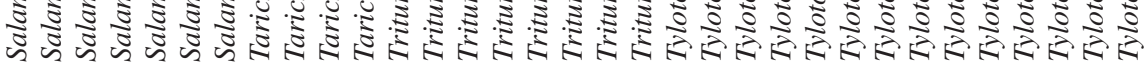

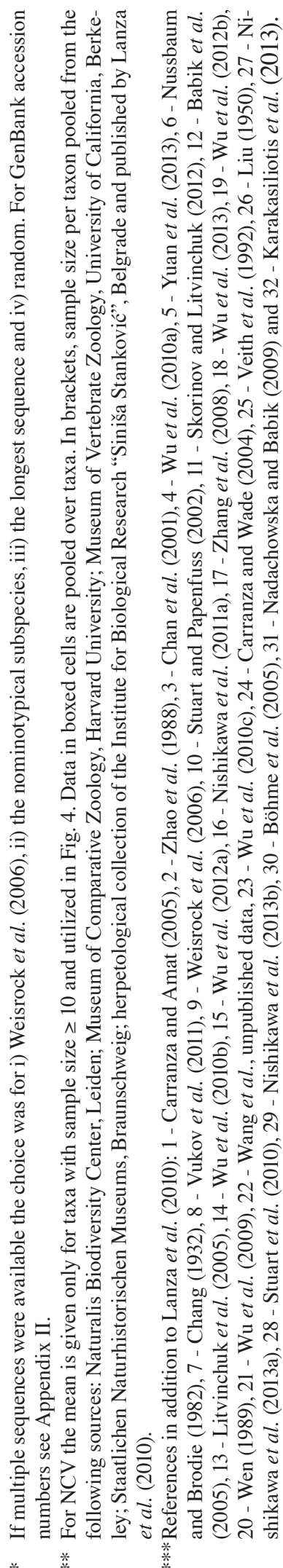




\section{Appendix II}

Molecular phylogeny of the family Salamandridae. To obtain a dated phylogeny for the genus Triturus we reconstructed the phylogeny of the entire family of the Salamandridae from full mitochondrial DNA (mtDNA) data under reference to seven fossil calibration points. The mtDNA data consisted of 11 sequences for eight Triturus species, 35 sequences for another 35 salamandrid species and four outgroup species (Zajc \& Arntzen, 1999; Zhang et al., 2008; Wielstra \& Arntzen, 2011). Following Steinfartz et al. (2007) and Wiens et al. (2011) we used as fossil calibration points the oldest taxon that can be confidently assigned to a given clade and then took the minimum age of the stratum to which that fossil is assigned: 1 - minimum age for the Salamandridae of 55 million years before present (Ma), based on the oldest known salamandrid fossil, the newt-like Koalliella genzeli Herre, 1950 dated to 65-55 Ma (Estes, 1981). The prior has a 95\% highest probability density (HPD) interval ranging from 54.4-74.3 Ma (median 57.7); 2 - minimum age for the clade consisting of Tylototriton, Echinotriton, and Pleurodeles of 44 Ma (HPD median 46.0, range 44.3-58.3), based on Chelotriton weigelti (Herre, 1935) (Milner, 2000) from the middle Eocene (Mammal Paleogene 13; Haubold and Thomae 1990) dated at $44 \mathrm{Ma}$ (Mertz et al., 2000); 3 - the clade of Notophthalmus and Taricha, minimum age $22 \mathrm{Ma}$ (HPD median 24.0, range 22.3-36.3) based on Taricha oligocenica (van Frank, 1955) from the upper Oligocene and dated to $22 \mathrm{Ma}$ (Estes, 1981); 4 - the crown group Triturus is at least $23.8 \mathrm{Ma}$ (median HPD 26.0, range 24.3-38.3), given fossils apparently related to Triturus marmoratus from the Lower Miocene (Estes 1981) and dated to 24.2-23.8 Ma (Böhme, 2003); 5 - the clade of Cynops, Laotriton, Pachytriton, and Paramesotriton that is at least $15 \mathrm{Ma}$ (median HPD 17.0, range 15.3-29.3), based on a fossil (Procynops miocenicus Young, 1965) (Estes, 1981), similar to Cynops orientalis from the Shanwang series (18-15 Ma; Qiu and Qiu, 1995); 6 - the clade of Salamandra and Lyciasalamandra is at least $33.9 \mathrm{Ma}$ (median HPD 36.7, range 34.4-53.3), based on the fossil Salamandra sansaniensis Lartet, 1851 from the Eocene (33.9-55.8 Ma; Milner, 2000); 7 - the clade of Chioglossa and Mertensiella is at least 23.03 Ma (median HPD 25.0, range 23.3-37.3), based on Chioglossa meini Estes \& Hoffstetter, 1976 and Mertensiella mera Hadrova, 1986 from the early Miocene (Ivanov, 2008).

We performed a combined phylogeny and divergence-time estimation using the Bayesian uncorrelated lognormal approach (Drummond et al., 2006) implemented in BEAST version 1.5.4 (Drummond and Rambaut, 2007). Analyses were conducted with separate partitions for different codon positions in 13 genes and yet other partitions for $12 \mathrm{~S}, 16 \mathrm{~S}$ and the combined RNA's (with rate parameters, rate heterogeneity and base frequencies unlinked across partitions, but clock and tree models linked), estimated base frequencies, with trees generated using a Yule speciation process and with nucleotide substitution models suggested by MrModelTest (Nylander, 2004). Temporal calibration points were treated as priors on clade ages, with a lognormal distribution (following Drummond et al., 2006), a standard deviation of one Ma (a standard but arbitrary number) and an offset equal to the estimated minimum age of the clade (allowing the calibration points to function as constraints on the minimum ages of clades). A mean of $5 \mathrm{Ma}$ was used for most clades, creating a 95\% highest probability density distribution (HPD) spanning from roughly 1 Ma older than the minimum age of the fossil to roughly 15 Ma older, with a median roughly $3 \mathrm{Ma}$ older than the fossil calibration point. This allows the fossil calibration point to constrain the minimum age of the clade, and allows for the possibility that the clade could be substantially older than the oldest known fossil. For two clades with greater uncertainty in the ages of the fossils (calibration points 1 and 6), we used a mean of $10 \mathrm{Ma}$ (such that the 95\% HPD extends to roughly $30 \mathrm{Ma}$ older than the fossil calibration point). We ran three replicate analyses of 100 million and two of 200 million generations in BEAST. All five runs yielded effective sample sizes (ESS) $>200$ for likelihood and ages of all clades as shown with Tracer, v. 1.5 (A. Rambaut and A.J. Drummond, available from http://beast.bio.ed.ac.uk/Tracer). Trees were combined using LogCombiner, after excluding the initial $90 \%$ (90-180 million generations) of each run as burn-in.

Secondly, we gathered ND1 / ND2 mtDNA sequence data from Genbank with the final consultation on 1 January 2014 , for altogether 101 salamandrid taxa (90 species and 11 subspecies), including the full mitogenomic data used above. Alignment of the proteincoding sequences was straightforward and done by eye, assisted by MacClade (Madisson \& Madisson, 2000). Data unavailable for one or the other gene fragment amounted to $12.7 \%$. The sequence data file is presented in the Online Supplementary Information. We analysed these data with the full mtDNA tree as a backbone constraint in PAUP* (Swofford, 2003), under likelihood 
settings determined by jModelTest 2.1.3 under default settings (Darriba et al., 2012). The tree was dated on the basis of 42 nodes for which the $95 \%$ confidence estimates (CI) were available from the full mtDNA phylogeny, with r8s v. 1.8 software (by M. Sanderson, made available at http://loco.biosci.arizona.edu/r8s/, The subroutine used was NPRS with Powell optimization with constraints set over the $95 \% \mathrm{CI}$ ). The resulting phylogeny for the family Salamandridae is described below. It is similar to that based on nuclear data (which had limited taxon sampling (Wiens, 2007)), indicating that the results based on mtDNA are not widely mis- leading (cf. Rubinoff and Holland, 2005). The erroneous reconstruction of a phylogeny e.g. due to incomplete lineage sorting or hybridization and introgression events, is likely to be most pronounced at the more recent branches of a tree. A case in point is Lissotriton montandoni in which the species' original mtDNA has throughout its range been replaced by that of the congeneric species $L$. vulgaris, with which it hybridizes (Babik et al., 2005; Zieliński et al., 2013).

The time calibrated phylogeny of the Salamandridae that we accept as the basis of the analytical work is as follows:

“)((()(((Calotriton_asper:34.61,((((Triturus_carnifex:4.51,Triturus_macedonicus:4.51)node01\{4.51,CI=3.22-5.59\} :2.19,(Triturus_cristatus:5.90,Triturus_dobrogicus:5.90)node02\{5.90,CI=6.07-9.17\}:0.79)node03 66.70,CI=6.509.64\}:0.40,(Triturus_ivanbureschi:5.27,Triturus_karelinii:5.27)node04\{5.27,CI=5.64-8.67\}:1.83)node05 $\{7.10, \mathrm{CI}=7.26-10.65\}: 11.06$,(Triturus_marmoratus:4.14,Triturus_pygmaeus:4.14)node06\{4.14,CI=3.83-6.20\}:14.01)nod e07\{18.16,CI=22.46-29.15\}:16.45)node08\{34.61,CI=33.80-41.85\}:2.70,(((Neurergus_crocatus:5.42,Neurergus_kaiseri:5.42)node09\{5.42\}:1.02,Neurergus_derjugini:6.44)node10\{6.44\}:5.73,(Neurergus_s_barani:1.81, Neurergus_s_strauchii:1.81)node11\{1.81\}:10.37)node12\{12.17,CI=12.17-17.31\}:21.81,(Ommatotriton_ophryticus: 12.05,Ommatotriton_vittatus:12.05)node13\{12.05\}:21.93)node14\{33.98,CI=32.68-40.32\}:3.33)node15

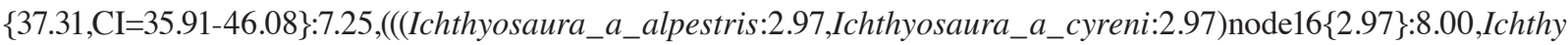
osaura_a_veluchiensis[KC149522]:10.97)node17\{10.97\}:31.44,(Lissotriton_boscai:28.20,(Lissotriton_helveticus: 24.54,(Lissotriton_italicus:16.30,((()(Lissotriton_montandoni:0.71,Lissotriton_v_ampelensis:0.71)node18 0.71$\}$ : 2.24,Lissotriton_v_vulgaris:2.95)node19\{2.95\}:0.10,Lissotriton_v_meridionalis:3.05)node20\{3.05\}:1.21,(Lissotriton_ v_schmidtlerorum:1.95,Lissotriton_v_graecus:1.95)node21\{1.95\}:2.31)node22\{4.26\}:0.55,Lissotriton_v_kosswigi [FJ588950]:4.81)node23\{4.81\}:1.64,Lissotriton_v_lantzi:6.45)node24\{6.45\}:9.85)node25 \{16.30\}:8.24)node26 $\{24.54\}: 3.66)$ node27 28.20$\}: 14.21)$ node2 $8\{42.41, \mathrm{CI}=37.48-47.45\}: 2.14)$ node29 $\{44.56, \mathrm{CI}=42.22-52.96\}: 1.49$, (((Cynops_cyanurus:20.70,Cynops_glaucus[KC762304]:20.70)node30\{20.70\}:1.85,((Cynops_fudingensis[GU301787] :8.83,Cynops_orientalis:8.83)node31\{8.83\}:4.73,_ynops_orphicus:13.56)node $32\{13.56$, CI=9.67-14.36\}:8.99) node33\{22.55,CI=19.68-26.62\}:2.14,(Cynops_ensicauda:23.82,(Laotriton_laoensis[DQ517808]:21.82,(((Pachytriton_ archospotus[GQ303628]:15.27,((Pachytriton_brevipes:7.86,Pachytriton_granulosus [DQ517798]:7.86) node34\{7.86,CI=7.86-11.79\}:6.22,(Pachytriton_feii[JX237735]:12.86,Pachytriton_changi[JX237745]:12.86) node35\{12.86\}:1.23)node36\{14.08\}:1.18)node37\{15.27\}:2.22,(Pachytriton_inexpectatus[JX907835]:14.11,Pachytrit on_moi[JX237747]:14.11)node38\{14.11\}:3.38)node39\{17.49,CI=17.49-24.59\}:3.57,((Paramesotriton_caudopunctatus:1 3.50,(Paramesotriton_longliensis[FJ169608]:2.28,Paramesotriton_zhijinensis[FJ169609]:2.28)node40\{2.28\} :11.22)node41\{13.50\}:5.69,(((Paramesotriton_chinensis:0.59,Paramesotriton_labiatus[FJ744601]:0.59)node42\{0.59\}: 10.13,Paramesotriton_hongkongensis:10.72)node 43 $\{10.72\}: 1.09$,(Paramesotriton_deloustali:7.44, (Paramesotriton_fuzhongensis:5.02,(Paramesotriton_guangxiensis:4.43,Paramesotriton_yunwuensis[GU980577] :4.43)node44\{4.43\}:0.58)node45\{5.02\}:2.43)node46\{7.44\}:4.37)node47\{11.81,CI=8.69-13.19\}:7.38)node48 $\{19.19$, $\mathrm{CI}=16.70-23.61\}: 1.87)$ node $49\{21.06\}: 0.76)$ node $50\{21.82, \mathrm{CI}=18.93-26.00\}: 2.00)$ node $51\{23.82, \mathrm{CI}=23.82-32.16\}: 0.87)$ node52\{24.69,CI=23.10-30.66\}:0.67,Cynops_pyrhogaster:25.36)node53\{25.36,CI=18.25-25.36\}:20.68) node54\{46.04,CI=44.85-58.03\}:6.36,(Euproctus_montanus:23.94,Euproctus_platycephalus:23.94)node55\{23.94, CI=20.75-27.17\}:28.47)node56 52.40,CI=48.83-63.25\}:10.58,((Notophthalmus_meridionalis:19.08,(Notophthalmus_ perstriatus:14.46,Notophthalmus_viridescens:14.46)node57\{14.46\}:4.61)node58 $\{19.08, \mathrm{CI}=14.50-20.82\}: 35.68$, (Taricha_granulosa:19.50,(Taricha_rivularis:15.37,Taricha_torosa:15.37)node59\{15.37\}:4.13)node60\{19.50, $\mathrm{CI}=13.63-19.50\}: 35.26)$ node61 $\{54.76, \mathrm{CI}=46.57-60.83\}: 8.22)$ node62\{62.98,CI=55.08-71.33\}:9.67,((Echinotriton_ andersoni:18.37,Echinotriton_chinhaiensis:18.37)node $63\{18.37, \mathrm{CI}=12.85-18.37\}: 9.58,(((($ Tylototriton_ asperrimus:10.62,Tylototriton_wenxianensis:10.62)node $64\{10.62, \mathrm{CI}=10.62-15.36\}: 5.25$, Tylototriton_ lizhengchangi[AB769532]:15.87)node65\{15.87\}:3.04,(Tylototriton_panhai[AB830735]:14.72,Tylototriton_ 
vietnamensis[HM770088]:14.72)node66\{14.72\}:4.19)node67\{18.91\}:1.02,(Tylototriton_hainanensis:9.40, (Tylototriton_notialis[HM462063]:8.03,Tylototriton_ziegleri[AB769539]:8.03)node68\{8.03\}:1.38)node69\{9.40\}:10.53) node70\{19.93\}:2.22,(((Tylototriton_kweichowensis:11.88,Tylototriton_verrucosus:11.88)node71\{11.88\}:1.34,((Tylototrit on_shanjing:9.05,Tylototriton_uyenoi[AB830729]:9.05)node72\{9.05\}:0.56,Tylototriton_yangi[AB830739]:9.61) node73\{9.61\}:3.61)node74\{13.22\}:4.94,Tylototriton_taliangensis:18.17)node75\{18.17\}:3.98)node76\{22.15\}:5.80) node77\{27.95,CI=21.74-27.95\}:21.48,(Pleurodeles_poireti:16.12,Pleurodeles_waltl:16.12)node78\{16.12, $\mathrm{CI}=15.53-22.23\}: 33.31)$ node79 $\{49.43, \mathrm{CI}=40.89-49.43\}: 23.23)$ node $80\{72.66, \mathrm{CI}=62.05-80.23\}: 17.22,(($ Chioglossa lusitanica:51.22,Mertensiella_caucasica:51.22)node81\{51.22,CI=43.43-55.64\}:15.30,((((Lyciasalamandra_ antalyana:11.70,_Lyciasalamandra_helverseni:11.70)node82\{11.70\}:1.57,((((Lyciasalamandra_basoglui:5.17, Lyciasalamandra_finikensis:5.17)node83\{5.17\}:1.81,_Lyciasalamandra_luschani:6.97)node84\{6.97\}:4.90,Lyciasalam andra_fazilae:11.87)node85\{11.87\}:0.92,Lyciasalamandra_billae:12.79)node86\{12.79\}:0.48)node87\{13.27\}:0.48,Lyci asalamandra_atifi:13.75)node88 $\{13.75\}: 0.99$,_Lyciasalamandra_flavimembris:14.73)node89\{14.73,CI=11.4316.29\}:21.26,(((((Salamandra_a_aurorae:0.44,Salamandra_a_atra:0.44)node90 $\{0.44\}: 7.66$, Salamandra_corsica: 8.10)node91\{8.10\}:2.97,Salamandra_lanzai:11.07)node92\{11.07\}:3.10,(Salamandra_i_semenovi:5.03,Salamandra_i_ infraimmaculata:5.03)node93 55.03\}:9.14)node94\{14.17\}:2.41,Salamandra_salamandra:16.58)node95 $\{16.58\}: 1.65$,Salamandra_algira:18.24)node96\{18.24\}:17.76)node97\{36.00,CI=31.49-38.36\}:30.53)node98 666.52 , CI=57.87-76.24\}:23.35)node99\{89.88,CI=72.62-98.43\}:16.65,Salamandrina_perspicillata[DQ517823]:106.53);"

All branches had posterior probabilities (pp) in excess of 0.99 , with three exceptions, namely $\mathrm{pp}=0.83$ for the branch leading to all taxa minus Salamandra perspicellata, $\mathrm{pp}=0.58$ for the branch leading to the genus Cynops and $\mathrm{pp}=0.95$ for the branch leading to Laotriton laoensis and the genus Pachytriton. Numbers following a colon are branch-lengths in Ma. Numbers in curly brackets are calibration points in $\mathrm{Ma}$; if accompanied by the code ' $\mathrm{CI}$ ' the three numbers refer to the estimate and to the $95 \%$ confidence interval of the estimate, respectively. GenBank accession numbers are provided in square brackets in cases of potential ambiguity (see also Appendix I). To draw the phylogeny as in Fig. 3 use e.g. TreeView (Page, 1996) after curly brackets have been replaced by straight brackets. To obtain phylogenetic trees suitable for character state analysis, taxa with no morphological data were trimmed from the data set with PhyUtility (Smith and Dunn, 2008). 


\section{Appendix III}

Illustrative cleared and stained specimens (upper part) and X-ray imagery (lower part) with collection registration numbers and vertebrae counts as follows: $\mathrm{A}$ and $\mathrm{B}$ - Ichthyosaura alpestris veluchiensis IBISS 7108, $\mathrm{NRBV}=13, \mathrm{NCV}=34$ and IBISS 7109, NRBV $=13$, $\mathrm{NCV}=27 ; \mathrm{C}$ and D - Triturus karelinii IBISS G22832, $\mathrm{NRBV}=13, \mathrm{NCV}=16$ with tail tip missing and G22825, $\mathrm{NRBV}=13$, NCV not available; E - Ichthyosaura alpestris veluchiensis ZMA.RENA.5308, NRBV = 13, NCV = 28; F - Pachytriton brevipes RMNH.RENA.5890,
$\mathrm{NRBV}=12, \mathrm{NCV}=23 ; \mathrm{G}-$ Taricha torosa ZMA. RENA.5011, NRBV $=12, \mathrm{NCV}=31 ; \mathrm{H}$ - Triturus karelinii RMNH.RENA.46931, NRBV = 13 (transitional - 13 left and 14 right) and NCV $=22$ with tail tip missing. J - CT-scan of a transitional sacral vertebra in T. dobrogicus (ZMA.RENA.9120). The sacral rib is developed on the left side on the 18th vertebra and at the right side on the 17th vertebra. The iliac bones of the pelvic girdle are attached to the corresponding sacral ribs of 17th (see insert) and 18th vertebra. The size bar represents $1 \mathrm{~cm}$.

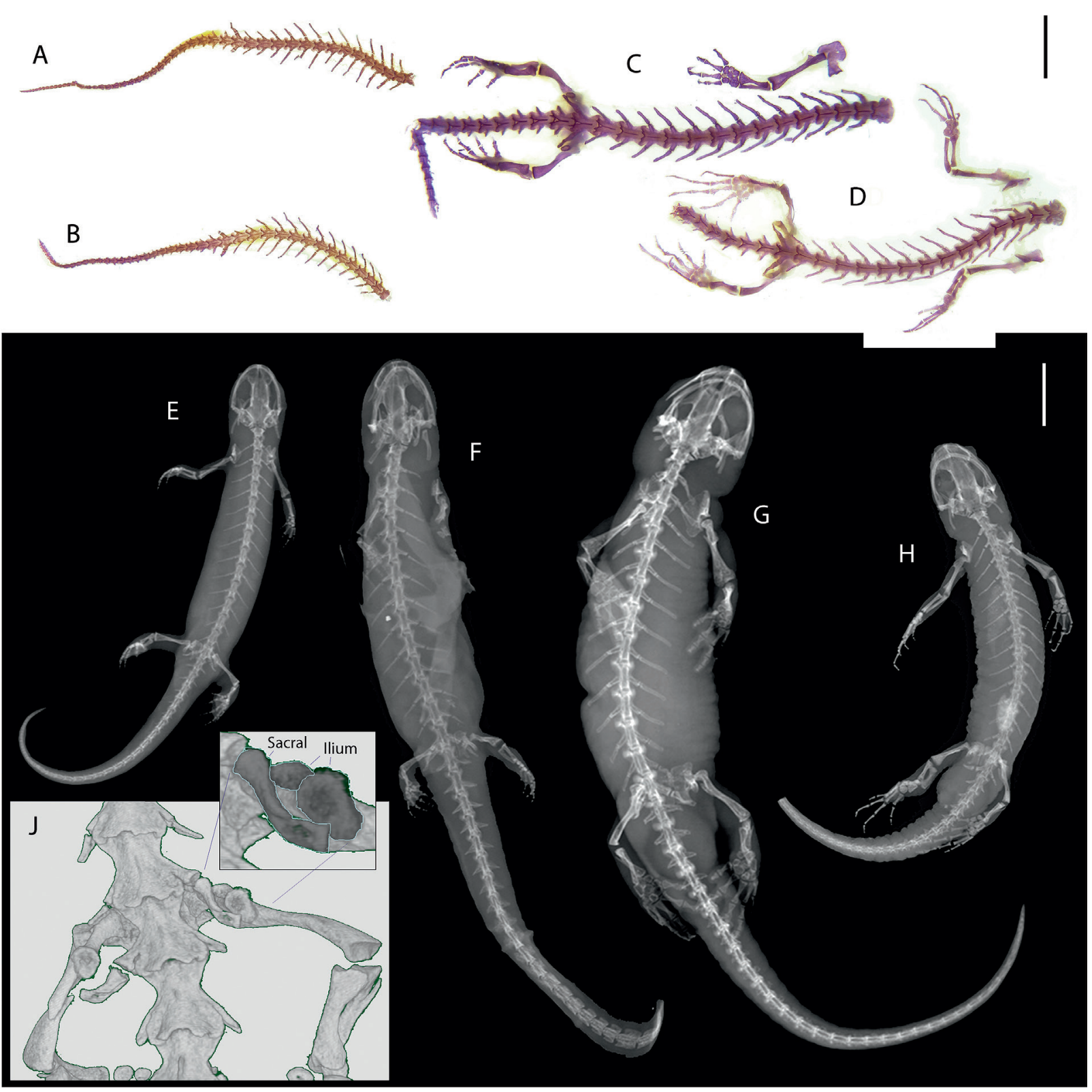




\section{Appendix IV}

Database of environmental data Bio 01 to Bio 19, altitude and slope, derived from Hijmans et al. (2012). Species distribution maps largely follow IUCN (2012).

\section{A - Environmental data}

\begin{tabular}{|c|c|c|c|c|c|c|c|c|c|}
\hline Taxon & Comments & $\begin{array}{l}\text { Range } \\
\left(\mathrm{km}^{2}\right)\end{array}$ & Bio 01 & Bio 02 & Bio 03 & Bio 04 & Bio 05 & Bio 06 & Bio 07 \\
\hline \multicolumn{2}{|l|}{ Calotriton asper } & 43349 & 77.673 & 84.834 & 35.131 & 5430.721 & 210.772 & -26.917 & 237.689 \\
\hline \multicolumn{2}{|l|}{ Chioglossa lusitanica } & 85023 & 127.696 & 86.315 & 40.100 & 4382.838 & 247.734 & 34.814 & 212.920 \\
\hline \multicolumn{2}{|l|}{ Cynops cyanurus } & 87981 & 156.699 & 106.361 & 45.438 & 4446.509 & 252.453 & 20.625 & 231.828 \\
\hline \multicolumn{2}{|l|}{ Cynops ensicauda } & 2565 & 215.724 & 55.833 & 29.274 & 4648.066 & 307.679 & 119.766 & 187.913 \\
\hline \multicolumn{2}{|l|}{ Cynops orientalis } & 294001 & 160.646 & 81.305 & 25.021 & 8371.431 & 318.931 & 0.310 & 318.621 \\
\hline \multicolumn{2}{|l|}{ Cynops orphicus } & 13131 & 191.560 & 75.390 & 31.467 & 5612.494 & 303.810 & 67.783 & 236.027 \\
\hline \multicolumn{2}{|l|}{ Cynops pyrrhogaster } & 411188 & 119.993 & 86.040 & 26.680 & 8144.233 & 282.823 & -33.821 & 316.644 \\
\hline \multicolumn{2}{|l|}{ Echinotriton andersoni } & 2880 & 215.447 & 55.578 & 29.140 & 4653.980 & 307.480 & 119.689 & 187.791 \\
\hline \multicolumn{2}{|l|}{ Echinotriton chinhaiensis } & 67 & 157.970 & 65.448 & 22.075 & 7864.448 & 301.463 & 13.836 & 287.627 \\
\hline \multicolumn{2}{|l|}{ Euproctus montanus } & 12185 & 124.781 & 60.908 & 29.142 & 5131.382 & 239.629 & 34.616 & 205.013 \\
\hline \multicolumn{2}{|l|}{ Euproctus platycephalus } & 3095 & 133.051 & 71.230 & 30.508 & 5608.977 & 266.068 & 36.130 & 229.939 \\
\hline \multicolumn{2}{|l|}{ Ichthyosaura a. alpestris } & 2196898 & 82.848 & 86.358 & 32.287 & 6420.025 & 224.946 & -39.534 & 264.480 \\
\hline \multicolumn{2}{|l|}{ Ichthyosaura a. cyreni } & 43193 & 108.514 & 86.843 & 39.379 & 4593.986 & 231.611 & 14.101 & 217.510 \\
\hline \multirow[t]{2}{*}{ Ichthyosaura a. veluchiensis } & Includes the northern Greek & & & & & & & & \\
\hline & lineage which has also NRBV 13 & 35831 & 114.874 & 106.367 & 36.060 & 6417.029 & 279.136 & -12.205 & 291.341 \\
\hline \multicolumn{2}{|l|}{ Laotriton laoensis } & 688 & 191.251 & 109.368 & 56.109 & 2353.856 & 268.100 & 74.983 & 193.118 \\
\hline \multicolumn{2}{|l|}{ Lissotriton boscai } & 345484 & 140.948 & 100.438 & 38.883 & 5363.559 & 289.894 & 33.246 & 256.648 \\
\hline \multicolumn{2}{|l|}{ Lissotriton helveticus } & 1909090 & 97.814 & 83.350 & 35.577 & 5362.989 & 225.506 & -5.685 & 231.191 \\
\hline Lissotriton italicus & & 114355 & 139.469 & 78.079 & 31.540 & 5865.031 & 275.406 & 32.401 & 243.005 \\
\hline Lissotriton $v$. ampelensis & Babik et al. (2005) & 36000 & 81.667 & 96.420 & 31.461 & 7354.181 & 235.853 & -65.373 & 301.226 \\
\hline Lissotriton v. graecus & Babik et al. (2005) & 2594 & 122.111 & 100.724 & 34.226 & 6642.641 & 281.910 & -8.299 & 290.209 \\
\hline Lissotriton v. kosswigi & Babik et al. (2005), & & & & & & & & \\
\hline & Schmidtler and Frantzen (2004) & 39037 & 105.977 & 98.412 & 34.897 & 6443.883 & 255.506 & -22.687 & 278.193 \\
\hline Lissotriton $v$. lantzi & Babik et al. (2005), & & & & & & & & \\
\hline & Schmidtler and Frantzen (2004) & 268674 & 72.338 & 98.188 & 31.618 & 7384.321 & 233.134 & -73.203 & 306.337 \\
\hline Lissotriton v. meridionalis & Babik et al. (2005) & 15206 & 121.504 & 85.230 & 30.691 & 6579.712 & 270.279 & -2.892 & 273.171 \\
\hline Lissotriton v. schmidtlerorum & Babik et al. (2005), & & & & & & & & \\
\hline & Schmidtler and Frantzen (2004) & 72714 & 140.514 & 103.629 & 36.148 & 6514.206 & 296.355 & 14.343 & 282.011 \\
\hline Lissotriton v. vulgaris & Babik et al. (2005) & 68656 & 77.699 & 92.564 & 28.716 & 8024.608 & 238.868 & -78.031 & 316.899 \\
\hline Lyciasalamandra atifi & & 3086 & 142.513 & 105.406 & 36.051 & 6632.815 & 299.789 & 11.052 & 288.737 \\
\hline Lyciasalamandra billae & & 87 & 171.471 & 111.701 & 37.908 & 6449.667 & 331.253 & 40.149 & 291.103 \\
\hline Lyciasalamandra fazilae & & 1005 & 171.042 & 121.051 & 40.777 & 6263.764 & 332.784 & 39.278 & 293.506 \\
\hline Lyciasalamandra flavimembris & & 525 & 171.691 & 111.918 & 37.463 & 6633.960 & 337.608 & 42.851 & 294.756 \\
\hline Lyciasalamandra helverseni & & 518 & 178.774 & 62.757 & 30.116 & 5230.069 & 286.724 & 82.361 & 204.363 \\
\hline Lyciasalamandra luschani & & 1452 & 161.463 & 113.826 & 39.444 & 6176.335 & 319.330 & 33.762 & 285.567 \\
\hline Mertensiella caucasica & & 38173 & 82.017 & 103.464 & 33.734 & 6901.154 & 240.638 & -60.902 & 301.540 \\
\hline Neurergus crocatus & & 19653 & 90.287 & 107.838 & 27.890 & 9635.701 & 293.128 & -86.434 & 379.562 \\
\hline Neurergus kaiseri & & 227 & 193.749 & 157.656 & 38.454 & 8663.009 & 415.542 & 10.872 & 404.670 \\
\hline Neurergus derjugini & & 821 & 116.150 & 146.939 & 35.554 & 9029.581 & 340.676 & -67.084 & 407.760 \\
\hline Neurergus s. barani & & 1867 & 117.438 & 105.292 & 27.544 & 9481.918 & 321.277 & -54.268 & 375.545 \\
\hline Neurergus s. strauchii & & 24156 & 97.488 & 108.628 & 28.455 & 9262.644 & 303.844 & -71.314 & 375.158 \\
\hline Notophthalmus meridionalis & & 117014 & 234.438 & 110.732 & 47.000 & 4428.673 & 342.670 & 106.754 & 235.916 \\
\hline Notophthalmus viridescens & & 5215453 & 107.078 & 119.850 & 32.663 & 8820.786 & 288.923 & -81.618 & 370.541 \\
\hline Ommatotriton ophryticus & Litvinchuk et al. (2005) & 412893 & 90.248 & 107.182 & 34.152 & 7108.960 & 255.373 & -53.660 & 309.033 \\
\hline Ommatotriton vittatus & Litvinchuk et al. (2005) & 77895 & 158.310 & 109.793 & 35.693 & 7079.256 & 320.313 & 15.436 & 304.877 \\
\hline Pachytriton brevipes & & 583823 & 179.934 & 82.106 & 28.493 & 7097.060 & 319.451 & 33.847 & 285.604 \\
\hline Pachytriton feii & & 427 & 131.433 & 71.792 & 23.269 & 8106.707 & 279.494 & -22.670 & 302.164 \\
\hline Pachytriton granulosus & & 60998 & 156.028 & 77.356 & 23.873 & 8419.440 & 314.585 & -2.780 & 317.365 \\
\hline Pachytriton moi & & 3257 & 155.402 & 79.507 & 27.986 & 7141.639 & 291.185 & 11.980 & 279.205 \\
\hline Paramesotriton caudopunctatus & & 48586 & 160.149 & 82.038 & 28.008 & 7328.505 & 303.324 & 14.939 & 288.386 \\
\hline Paramesotriton chinensis & & 163067 & 164.152 & 76.462 & 25.743 & 7522.468 & 309.882 & 17.401 & 292.481 \\
\hline Paramesotriton deloustali & & 29597 & 218.333 & 79.882 & 39.346 & 4459.567 & 309.583 & 108.759 & 200.824 \\
\hline Paramesotriton fuzhongensis & & 7486 & 183.010 & 81.919 & 29.469 & 6779.370 & 313.978 & 40.836 & 273.142 \\
\hline
\end{tabular}




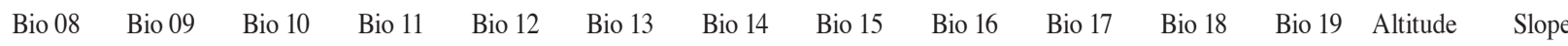

\begin{tabular}{|c|c|c|c|c|c|c|c|c|c|c|c|c|c|}
\hline 77.002 & 82.797 & 149.617 & 12.153 & 1062.020 & 115.092 & 64.426 & 15.991 & 308.821 & 222.726 & 240.726 & 252.319 & 1281.094 & 8.486 \\
\hline 82.313 & 184.236 & 185.833 & 74.198 & 1137.781 & 158.569 & 27.395 & 43.227 & 435.366 & 114.586 & 126.214 & 413.120 & 459.812 & 3.803 \\
\hline 205.858 & 95.171 & 205.874 & 93.588 & 1002.517 & 207.422 & 12.181 & 85.863 & 575.773 & 40.688 & 572.820 & 40.719 & 1924.125 & 4.852 \\
\hline 252.094 & 155.604 & 274.166 & 155.604 & 2452.615 & 333.030 & 126.421 & 31.005 & 834.299 & 409.558 & 716.872 & 409.876 & 119.891 & 2.757 \\
\hline 232.324 & 73.980 & 265.264 & 49.837 & 1451.310 & 243.231 & 39.775 & 52.018 & 618.008 & 150.005 & 548.853 & 172.421 & 228.942 & 3.040 \\
\hline 227.504 & 137.106 & 258.098 & 115.928 & 1596.153 & 259.067 & 32.233 & 57.466 & 677.007 & 119.574 & 615.034 & 163.915 & 478.242 & 4.848 \\
\hline 203.108 & 40.647 & 224.889 & 17.000 & 1822.945 & 261.294 & 73.490 & 40.423 & 691.952 & 242.651 & 652.189 & 276.619 & 414.111 & 4.072 \\
\hline 248.995 & 155.345 & 274.056 & 155.345 & 2448.342 & 331.625 & 126.144 & 30.579 & 831.821 & 409.766 & 711.006 & 410.049 & 121.745 & 2.790 \\
\hline 256.925 & 82.731 & 256.925 & 56.612 & 1426.224 & 198.104 & 49.597 & 41.045 & 505.642 & 176.209 & 505.642 & 187.627 & 191.090 & 5.206 \\
\hline 104.034 & 191.188 & 193.679 & 64.915 & 738.779 & 99.278 & 13.997 & 42.632 & 281.526 & 75.045 & 96.940 & 236.743 & 613.659 & 7.635 \\
\hline 95.837 & 206.950 & 208.969 & 68.162 & 706.144 & 104.599 & 9.436 & 50.420 & 276.337 & 52.731 & 67.627 & 261.550 & 649.866 & 5.006 \\
\hline 128.134 & 36.320 & 163.477 & -1.071 & 836.176 & 98.011 & 49.155 & 23.041 & 273.722 & 158.331 & 252.846 & 183.558 & 518.326 & 2.913 \\
\hline 76.284 & 167.642 & 169.604 & 52.758 & 964.548 & 118.605 & 45.534 & 25.127 & 319.732 & 167.384 & 177.473 & 278.651 & 719.797 & 5.741 \\
\hline 54.749 & 197.634 & 198.327 & 35.077 & 871.093 & 131.032 & 22.766 & 48.282 & 356.114 & 85.571 & 86.298 & 333.449 & 918.986 & 7.433 \\
\hline 210.278 & 158.355 & 213.612 & 156.205 & 1681.067 & 384.395 & 4.843 & 94.099 & 974.403 & 30.715 & 804.320 & 34.890 & 1401.971 & 6.780 \\
\hline 88.744 & 211.064 & 212.476 & 75.625 & 767.874 & 106.225 & 12.780 & 48.919 & 297.844 & 63.464 & 67.474 & 284.065 & 7.210 & 2.522 \\
\hline 97.163 & 95.393 & 166.729 & 29.603 & 855.795 & 94.447 & 50.259 & 18.037 & 263.198 & 167.223 & 202.315 & 227.116 & 307.532 & 1.863 \\
\hline 111.332 & 210.656 & 216.320 & 68.735 & 722.548 & 96.602 & 25.673 & 36.263 & 267.941 & 93.675 & 103.541 & 228.384 & 425.829 & 3.757 \\
\hline 156.711 & -3.523 & 171.289 & -17.283 & 698.617 & 104.945 & 35.706 & 38.783 & 277.976 & 111.749 & 267.060 & 121.871 & 632.747 & 3.690 \\
\hline 74.651 & 200.343 & 207.412 & 38.051 & 740.694 & 104.703 & 25.350 & 39.187 & 283.017 & 89.244 & 96.664 & 254.577 & 646.420 & 5.231 \\
\hline 57.598 & 180.384 & 186.509 & 21.885 & 748.590 & 95.823 & 39.553 & 27.931 & 256.045 & 123.777 & 141.803 & 237.940 & 735.657 & 4.922 \\
\hline & 4.130 & & & & & & & & & & & & 6.505 \\
\hline 119.534 & 126.489 & 205.708 & 37.528 & 878.193 & 107.012 & 43.817 & 24.907 & 286.935 & 154.564 & 187.705 & 199.667 & 394.558 & 3.524 \\
\hline 70.531 & 222.528 & 224.780 & 59.743 & & & & & & & & & & 3.098 \\
\hline 166.640 & -9.946 & 175.444 & -31.029 & 665.638 & 93.382 & 32.225 & 37.210 & 258.707 & 103.036 & 252.026 & 1.438 & 8.016 & 1.625 \\
\hline 59.013 & 226.753 & 227.236 & 59.013 & 874.702 & 179.433 & 5.605 & 81.520 & 484.150 & 26.230 & 30.886 & 484.150 & 7.544 & 8.810 \\
\hline 92.471 & 254.713 & 255.126 & 92.471 & 880.172 & 192.598 & 3.736 & 90.092 & 525.287 & 18.080 & 20.494 & 525.287 & 317.793 & 9.559 \\
\hline & 252.853 & & & & & & & & & & & & 4.325 \\
\hline 92.093 & 258.802 & 259.095 & 91.739 & 999.375 & 230.425 & 3.625 & 91.189 & 586.722 & 22.413 & 22.819 & 586.650 & 291.152 & 5.400 \\
\hline 122.840 & 245.923 & 246.295 & 115.118 & 712.757 & 170.037 & 0.869 & 94.838 & 416.998 & 4.573 & 11.290 & 344.521 & 262.797 & 6.523 \\
\hline 85.506 & 241.204 & 241.534 & & 829.236 & 194.100 & 4.000 & & & & & .216 & & 7.575 \\
\hline 91.033 & 100.085 & 167.428 & -8.050 & 840.157 & 104.426 & 41.973 & 27.826 & 284.243 & 143.209 & 172.233 & 207.760 & 1270.011 & 8.613 \\
\hline 21.324 & 209.289 & 209.540 & -36.605 & 635.210 & 111.990 & 3.263 & 71.336 & 304.327 & 11.953 & 15.059 & 240.890 & 1871.327 & 8.681 \\
\hline 82.595 & 303.599 & 303.599 & 82.264 & 426.595 & 89.194 & 0.000 & 88.317 & 222.203 & 0.053 & 0.062 & 222.176 & 943.687 & 9.955 \\
\hline 17.787 & 230.597 & 231.055 & -2.174 & 652.493 & 120.565 & 0.000 & & & 0.223 & 0.512 & 303.536 & 178 & 9.760 \\
\hline 19.147 & 236.831 & 236.857 & -5.267 & 586.658 & 82.986 & 2.461 & 62.866 & 231.667 & 12.097 & 13.884 & 230.251 & 1443.330 & 7.510 \\
\hline 22.559 & 215.260 & 215.275 & -20.751 & 796.316 & 116.448 & 5.228 & 61.634 & 326.225 & 22.379 & 23.095 & 291.763 & 1642.133 & 6.434 \\
\hline 271.766 & 192.679 & 283.672 & 171.986 & 886.750 & 175.231 & 21.550 & 61.971 & 399.418 & 88.891 & 330.192 & 106.762 & 83.162 & 0.614 \\
\hline 162.075 & 46.422 & 215.966 & -11.778 & 1102.969 & 124.059 & 61.693 & 21.475 & 343.447 & 207.806 & & 242.439 & 239.491 & 0.866 \\
\hline 83.468 & 133.712 & 178.423 & -3.110 & 671.061 & 88.681 & 28.228 & 34.816 & 236.378 & 96.819 & 133.385 & 179.961 & 1144.411 & 5.466 \\
\hline 66.948 & 245.351 & 246.668 & 66.312 & 758.092 & 145.932 & 4.188 & 76.462 & 391.375 & 20.008 & 23.687 & 388.762 & 657.142 & 3.943 \\
\hline 222.417 & 106.795 & 265.840 & 84.418 & 1621.177 & 273.299 & 42.674 & 56.297 & 729.864 & 154.272 & 571.048 & 195.703 & 375.349 & 3.932 \\
\hline 187.225 & 43.012 & 232.361 & 23.482 & 1794.157 & 302.496 & 48.115 & 51.014 & 758.883 & 177.501 & 678.824 & 208.621 & 765.726 & 8.531 \\
\hline 218.754 & 70.877 & 261.132 & 44.624 & 1501.651 & 248.563 & 44.799 & 48.569 & 618.272 & 163.674 & 550.055 & 190.490 & 275.223 & 23.395 \\
\hline 208.645 & 78.600 & 241.165 & 58.668 & 1612.209 & 288.724 & 47.540 & 56.781 & 735.181 & 170.576 & 603.971 & 183.417 & 806.724 & 7.566 \\
\hline 218.090 & 61.301 & 249.517 & 60.654 & 1269.464 & 212.511 & 32.844 & 55.293 & 554.252 & 114.636 & 485.916 & 115.640 & 668.754 & 4.282 \\
\hline 217.282 & 88.809 & 257.562 & 65.007 & 1643.061 & 265.473 & 43.950 & 50.295 & 668.790 & 164.212 & 581.151 & 202.856 & 397.759 & 4.908 \\
\hline 266.758 & 162.412 & 267.962 & 156.043 & 1761.586 & 357.799 & 13.972 & 84.132 & 972.558 & 68.138 & 962.426 & 72.183 & 369.000 & 4.818 \\
\hline 225.958 & 110.449 & 262.606 & 90.801 & 1552.530 & 289.038 & 45.605 & 60.078 & 722.674 & 146.882 & 576.456 & 180.704 & 454.425 & 4.427 \\
\hline
\end{tabular}


Cont. A - Environmental data

\begin{tabular}{|c|c|c|c|c|c|c|c|c|c|}
\hline Taxon & Comments & $\begin{array}{r}\text { Range } \\
\left(\mathrm{km}^{2}\right)\end{array}$ & Bio 01 & Bio 02 & Bio 03 & Bio 04 & Bio 05 & Bio 06 & Bio 07 \\
\hline \multicolumn{2}{|c|}{ Paramesotriton guangxiensis } & 565 & 209.391 & 75.669 & 35.712 & 4971.818 & 303.297 & 93.904 & 209.393 \\
\hline \multicolumn{2}{|c|}{ Paramesotriton hongkongensis } & 25974 & 223.743 & 70.977 & 32.435 & 5146.707 & 320.039 & 105.047 & 214.992 \\
\hline \multicolumn{2}{|c|}{ Paramesotriton labiatus } & 134874 & 178.751 & 80.397 & 28.216 & 7079.104 & 315.574 & 34.387 & 281.187 \\
\hline \multicolumn{2}{|c|}{ Pleurodeles poireti } & 2681 & 178.648 & 92.264 & 38.345 & 5145.231 & 308.518 & 70.866 & 237.653 \\
\hline \multicolumn{2}{|c|}{ Pleurodeles walt } & 536648 & 150.244 & 109.364 & 38.662 & 5854.752 & 311.639 & 31.086 & 280.554 \\
\hline \multicolumn{2}{|c|}{ Salamandra a. atra } & 188564 & 43.808 & 82.631 & 30.573 & 6397.965 & 183.178 & -80.823 & 264.001 \\
\hline \multicolumn{2}{|c|}{ Salamandra a. aurorae } & 129 & 89.787 & 86.669 & 29.551 & 6951.669 & 243.898 & -43.378 & 287.276 \\
\hline \multicolumn{2}{|c|}{ Salamandra algira } & 29270 & 151.054 & 106.350 & 37.913 & 5757.217 & 307.177 & 30.697 & 276.480 \\
\hline \multicolumn{2}{|c|}{ Salamandra corsica } & 6923 & 110.140 & 56.406 & 27.211 & 5214.736 & 224.640 & 21.362 & 203.278 \\
\hline \multicolumn{2}{|c|}{ Salamandra i. infraimmaculata } & 90459 & 121.767 & 113.593 & 34.601 & 7455.241 & 296.989 & -28.724 & 325.713 \\
\hline \multicolumn{2}{|c|}{ Salamandra i. semenovi } & 44534 & 100.862 & 111.429 & 29.018 & 9373.376 & 304.887 & -71.801 & 376.688 \\
\hline \multicolumn{2}{|c|}{ Salamandra lanzai } & 1250 & 31.989 & 72.855 & 29.676 & 5841.851 & 162.560 & -77.895 & 240.455 \\
\hline \multicolumn{2}{|c|}{ Salamandra salamandra } & 3592466 & 98.872 & 90.333 & 33.637 & 6258.459 & 243.733 & -22.050 & 265.783 \\
\hline \multicolumn{2}{|c|}{ Salamandrina perspicillata } & 117141 & 121.730 & 83.270 & 31.384 & 6184.554 & 266.989 & 6.818 & 260.171 \\
\hline \multicolumn{2}{|c|}{ Taricha granulosa } & 651184 & 70.251 & 97.087 & 38.630 & 5245.136 & 211.730 & -34.403 & 246.133 \\
\hline \multicolumn{2}{|c|}{ Taricha rivularis } & 21243 & 119.864 & 136.692 & 53.253 & 4228.157 & 269.530 & 13.531 & 255.998 \\
\hline \multicolumn{2}{|c|}{ Taricha torosa } & 71315 & 137.827 & 139.503 & 52.346 & 4572.156 & 288.261 & 20.253 & 268.008 \\
\hline \multicolumn{2}{|c|}{ Triturus carnifex } & 549616 & 105.766 & 85.937 & 30.890 & 6605.643 & 253.924 & -19.391 & 273.315 \\
\hline \multicolumn{2}{|c|}{ Triturus cristatus } & 8571399 & 59.752 & 83.351 & 25.692 & 8758.810 & 231.596 & -98.091 & 329.687 \\
\hline \multicolumn{2}{|c|}{ Triturus dobrogicus } & 456514 & 105.715 & 97.461 & 30.390 & 7788.760 & 270.598 & -44.934 & 315.532 \\
\hline Trituru: & Wielstra et al. (2010) & 46583 & 110.435 & 101.809 & 33.062 & 7176.147 & 273.783 & -29.572 & 303.355 \\
\hline \multicolumn{2}{|c|}{ Triturus karelinii } & 76333 & 105.021 & 106.829 & 31.375 & 8062.161 & 284.305 & -51.232 & 335.537 \\
\hline \multicolumn{2}{|c|}{ Triturus macedonicus } & 252541 & 106.572 & 99.467 & 33.390 & 6764.289 & 266.150 & -26.996 & 293.145 \\
\hline \multicolumn{2}{|c|}{ Triturus marmoratus } & 773002 & 114.631 & 94.062 & 38.308 & 5295.555 & 250.613 & 8.253 & 242.361 \\
\hline \multicolumn{2}{|c|}{ Triturus pygmaeus } & 258462 & 157.372 & 106.991 & 38.470 & 5765.692 & 318.108 & 42.017 & 276.091 \\
\hline \multicolumn{2}{|c|}{ Tylototriton asperrimus } & 367495 & 175.161 & 79.771 & 28.714 & 7029.887 & 310.896 & 33.382 & 277.514 \\
\hline \multicolumn{2}{|c|}{ Tylototriton kweichowensis } & 44968 & 129.965 & 86.455 & 33.168 & 5980.856 & 254.073 & -3.063 & 257.137 \\
\hline \multicolumn{2}{|c|}{ Tylototriton panhai } & 936 & 256.637 & 121.322 & 54.013 & 2141.555 & 357.322 & 134.811 & 222.511 \\
\hline \multicolumn{2}{|c|}{ Tylototriton taliangensis } & 35381 & 108.711 & 99.130 & 38.193 & 5439.404 & 223.535 & -32.844 & 256.379 \\
\hline Tylototı & & 4003 & 233.268 & 120.046 & 50.667 & 2430.491 & 341.645 & 106.897 & 234.748 \\
\hline Tylototı & & 436372 & 201.583 & 114.574 & 49.039 & 3529.276 & 296.421 & 65.098 & 231.323 \\
\hline Tylototı & & 36555 & 222.436 & 77.977 & 37.101 & 4737.562 & 317.464 & 110.102 & 207.362 \\
\hline
\end{tabular}

\section{B - brief description of the bioclimatic variables, from http://www.worldclim.org/bioclim.}

Bio01 = annual mean temperature

Bio02 $=$ mean diurnal range $($ mean of monthly $(\max$ temp $-\min$ temp $))$

Bio03 $=$ isothermality $(\mathrm{Bio} 2 / \mathrm{Bio} 7)(* 100)$

Bio04 $=$ temperature seasonality (standard deviation $* 100)$

Bio05 $=$ max temperature of warmest month

Bio06 $=$ min temperature of coldest month

Bio07 = temperature annual range (Bio5-Bio6)

Bio08 $=$ mean temperature of wettest quarter

Bio09 $=$ mean temperature of driest quarter

Biol0 $=$ mean temperature of warmest quarter

Biol1 $=$ mean temperature of coldest quarter

Biol2 $=$ annual precipitation

Bio13 = precipitation of wettest month

Biol4 $=$ precipitation of driest month

Bio15 $=$ precipitation seasonality (coefficient of variation)

Bio16 $=$ precipitation of wettest quarter

Biol7 $=$ precipitation of driest quarter

Biol $8=$ precipitation of warmest quarter

Bio19 $=$ precipitation of coldest quarter 
Bio 08 Bio $09 \quad$ Bio $10 \quad$ Bio $11 \quad$ Bio 12 $\quad$ Bio 13 $\quad$ Bio 14 $\quad$ Bio 15 $\quad$ Bio $16 \quad$ Bio $17 \quad$ Bio 18 $\quad$ Bio 19 Altitude $\quad$ Slope

\begin{tabular}{|c|c|c|c|c|c|c|c|c|c|c|c|c|c|}
\hline 264.051 & 155.781 & 264.051 & 139.995 & 1738.773 & 339.288 & 26.892 & 79.023 & 956.743 & 100.965 & 956.743 & 113.039 & 428.044 & 4.268 \\
\hline 280.452 & 164.451 & 281.532 & 152.269 & 1730.463 & 308.671 & 26.116 & 2.982 & 867.192 & & 864.485 & 107.493 & & 1.517 \\
\hline 221.553 & 102.259 & 63.539 & 83.032 & 1539.581 & 268.224 & 46.569 & 56.343 & 706.192 & 157.327 & 542.000 & 186.558 & 462.910 & 4.497 \\
\hline 131.170 & 241.747 & 48.336 & 116.985 & 754.820 & 132.311 & 3.336 & 67.776 & 364.029 & 27.779 & & & & 2.359 \\
\hline 108.860 & 226.321 & 28.701 & 79.212 & 530.482 & 74.614 & & 49.644 & & & & & & 1.898 \\
\hline 113.693 & -22.192 & 124.309 & -38.724 & 1187.587 & 143.8 & 64.996 & & & & & 221.279 & 1370. & 10.072 \\
\hline 151.008 & 7.528 & & -1.031 & 826.441 & 94.945 & & 29.087 & & & & & & 11.885 \\
\hline 92.467 & 226.098 & 228.907 & 81.264 & 738.541 & 120.501 & & & & & & & & 6.120 \\
\hline 89.111 & 177.895 & 0.497 & 49.821 & 785.399 & 102.543 & 17.0 & & & & 106. & & & 9.354 \\
\hline 51.162 & 212.690 & 23 & 23.588 & 672.642 & 120.264 & .432 & & & & & & & 5.362 \\
\hline 22.339 & 218.60 & & -20.209 & 697.224 & & 2.425 & & & & & & & 8.533 \\
\hline 15.753 & .438 & & & 1320.091 & 127. & & & & & & & & 12.393 \\
\hline 116.488 & & & & & & & & & & & & & 3.205 \\
\hline 99.553 & 185.188 & & 45.199 & & & & & & & & & & 4.596 \\
\hline 25.254 & 129.406 & & 7.625 & 1718.2 & 14 & 46. & & & & & & & 6.938 \\
\hline 73.387 & 173.780 & & 69.882 & 1331.618 & & & & & & & & & 4.433 \\
\hline 86.681 & 194 & & & & & & & & & & & & 4.435 \\
\hline 125.383 & & 190.077 & 21.271 & & & 46.0 & & & & & & & 4.197 \\
\hline 154.204 & -22.358 & 169.462 & -54.482 & 646.911 & & & & & & & & & 0.829 \\
\hline 189.015 & & & & & & & & & & & & & 0.673 \\
\hline 103.015 & 132.216 & 0.703 & 16.980 & 669.002 & 92.010 & & & & & & & & 3.224 \\
\hline 112.279 & 123.9 & & & & & & & & & & & & 3.457 \\
\hline 75.314 & & 192.463 & 19.369 & 883.554 & 112.370 & 40.622 & & & & & & & 5.331 \\
\hline 85.266 & & & & & & & & & & & & & 1.912 \\
\hline 103.715 & 232.980 & & & & & & & & & & & & 1.856 \\
\hline 234.436 & 87.624 & 259.957 & 79.541 & 1405.669 & 239.609 & 34.253 & 59.668 & & 123.694 & & 130.826 & 512.686 & 3.786 \\
\hline 200.616 & & & 46.305 & 1002.634 & & & & & & & & & 5.628 \\
\hline 264.285 & 225.721 & & 225.431 & & & & & & & & & & 3.033 \\
\hline 173.556 & 33.717 & 173.972 & 33.717 & 1111.745 & & & 87.901 & & 28.233 & & 28.233 & 2308.301 & 10.151 \\
\hline 241.365 & 212.060 & 259.603 & 197.365 & 1069.867 & 203.730 & 6.045 & & & & & & & 5.069 \\
\hline 233.465 & 158.290 & 237.191 & 149.450 & 1685.401 & & & & & & & & 1057.664 & 6.055 \\
\hline 274.619 & 165.742 & 275.381 & 156.587 & 1633.707 & 330.138 & 14.516 & 83.983 & 908.145 & 68.822 & 903.445 & 74.196 & 261.585 & 2.963 \\
\hline
\end{tabular}

C - loadings of 15 environmental variables to four PCA axes with eigenvalues larger than unity. High loadings $(>0.8)$ are in boldface type and moderately high loadings $(0.6<$ loading $<0.8)$ are in italics.

\begin{tabular}{|c|c|c|c|c|}
\hline Environmental variable & PCA1 & PCA2 & PCA3 & PCA4 \\
\hline Bio02 & -0.124 & -0.813 & -0.013 & 0.099 \\
\hline Bio03 & 0.366 & -0.601 & -0.630 & -0.073 \\
\hline Bio04 & -0.560 & 0.061 & 0.781 & 0.239 \\
\hline Bio05 & 0.589 & -0.445 & 0.600 & -0.149 \\
\hline Bio06 & 0.897 & -0.057 & -0.144 & -0.340 \\
\hline Bio08 & 0.764 & 0.421 & 0.101 & 0.056 \\
\hline Biol0 & 0.775 & -0.165 & 0.571 & -0.128 \\
\hline Biol1 & 0.925 & -0.159 & -0.158 & -0.255 \\
\hline Biol3 & 0.846 & 0.258 & -0.021 & 0.386 \\
\hline Biol4 & -0.058 & 0.914 & -0.048 & -0.085 \\
\hline Bio15 & 0.576 & -0.680 & 0.096 & 0.341 \\
\hline Biol6 & 0.834 & 0.250 & -0.047 & 0.414 \\
\hline Bio17 & -0.026 & 0.925 & -0.062 & -0.107 \\
\hline Bio18 & 0.663 & 0.559 & -0.038 & 0.405 \\
\hline Altitude & -0.394 & -0.233 & -0.227 & 0.724 \\
\hline Variance explained (\%) & 40.0 & 27.4 & 12.1 & 9.6 \\
\hline
\end{tabular}




\section{Appendix V}

Clustering of 21 environmental variables on the basis of pairwise correlation coefficients (Pearson's productmoment correlations, $r$ ) with the UPGMA method. Note the presence of six clusters within which variables are correlated at $r>0.5$. Selected variables are underlined.

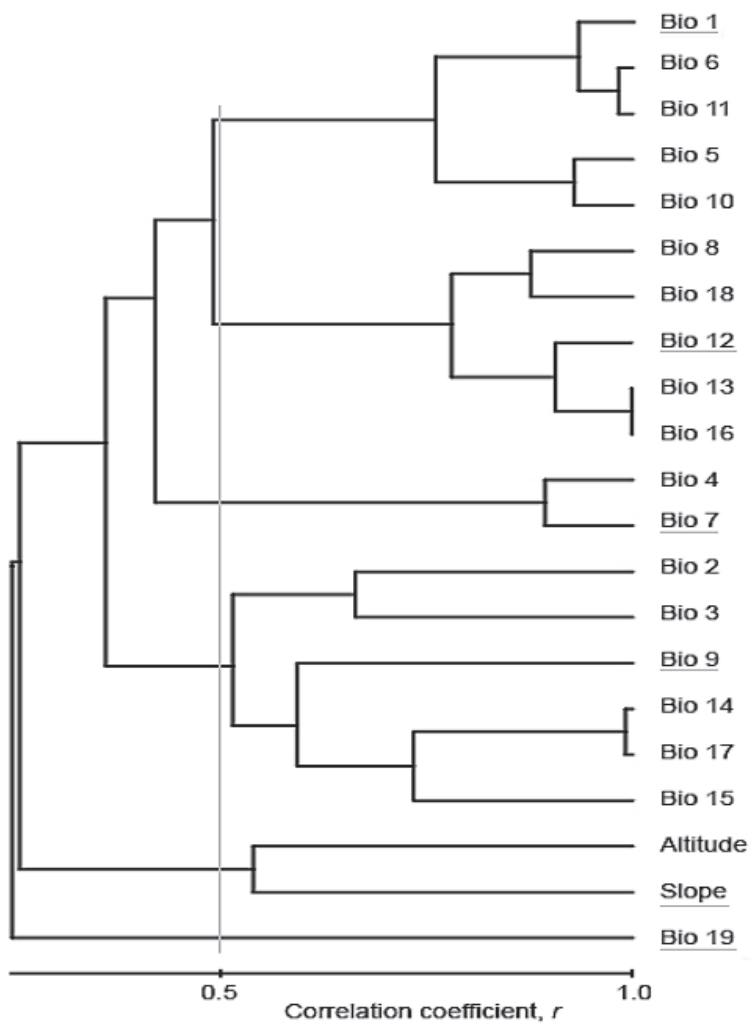

\section{Appendix VI}

Drawn images of a variety of salamander species, as used in Figs 1 and 5. Artwork Bas Blankevoort (C) Naturalis Biodiversity Center.

Species depicted are: a. Chioglossa lusitanica, b. Lyciasalamandra antalyana, c. Proteus anguinus, d. Salamandra infraimmaculata, e. Speleomantes flavus, f. Triturus marmoratus, g. Triturus dobrogicus and h. Lissotriton vulgaris.

Reproduction of the images is free under citation of the source publication.

a

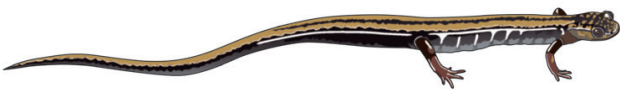

b

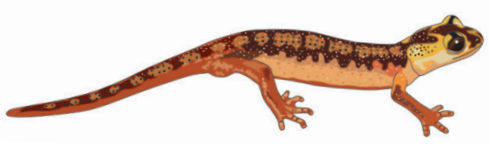

c
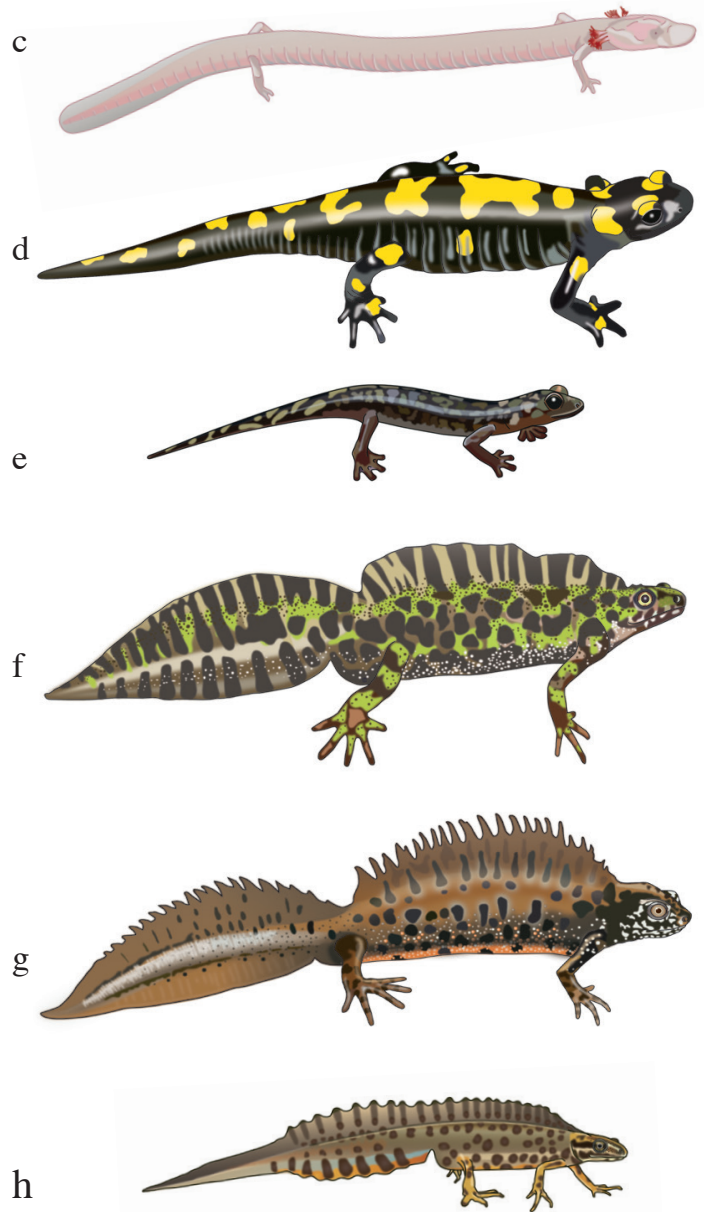


\section{Appendix VII}

Phylogenetic relationships for 81 salamandrid salamanders with NRBV documented. Branch lengths represent the amount of morphological change, as shown in legend. Right-headed arrows represent inferred gains and left-headed arrows represent inferred losses of vertebrae. Morphological change not unambiguously allocated to a single branch is shown in red.
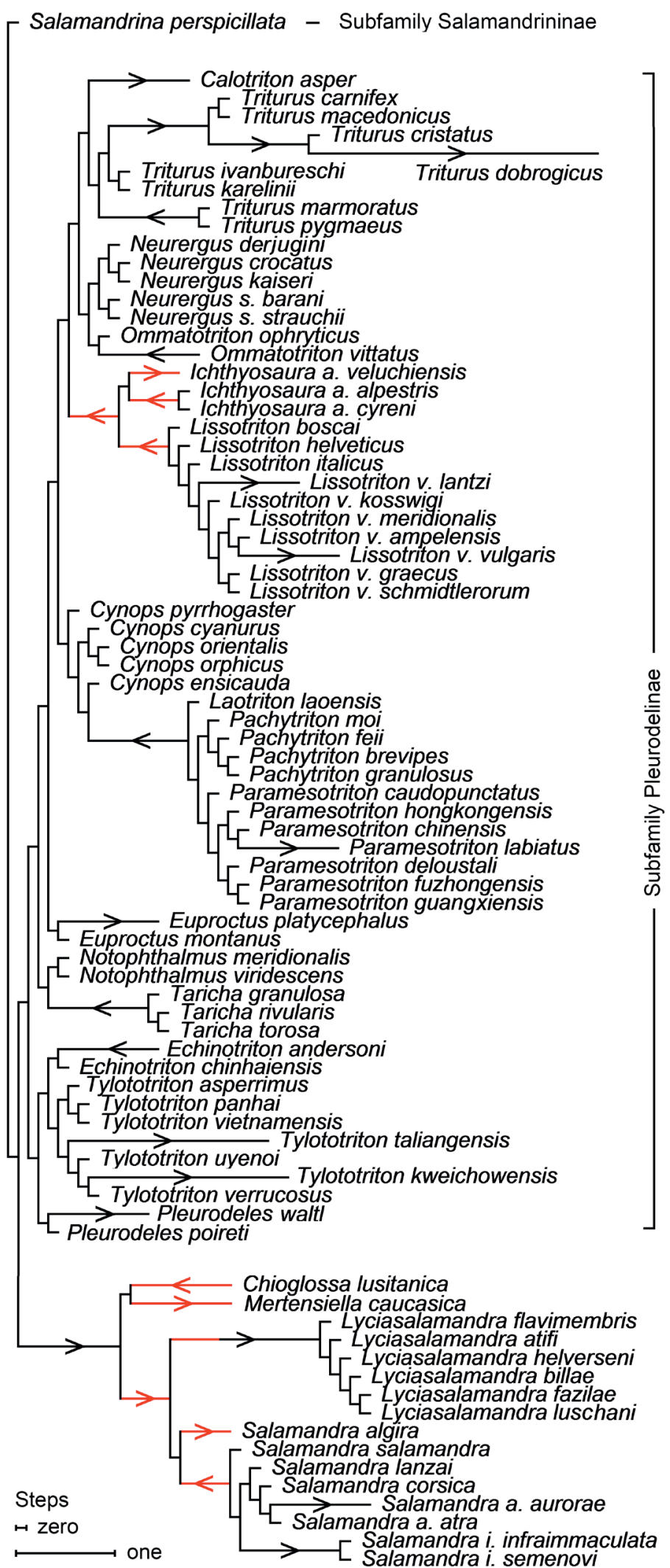